\title{
Fragments of Globalization: Archaeological Porcelain and the Early Colonial Dynamics in the Philippines
}

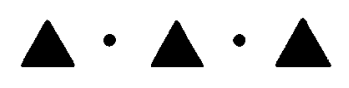

LI MIN

\section{INTRODUCTION}

SOCIAL HISTORIANS CRITICAL of a Eurocentric perspective on the advent of the early modern world system after 1492 have stressed the scale and importance of preexisting trade networks and the dynamic relationships between these networks and Europe's eventual rise to prominence. Abu-Lughod (1989) argues for the presence of a thirteenth-century world system before the emergence of European hegemony after the sixteenth century. Frank (1998) problematizes the very notion of a European hegemony before 1800 and emphasizes the contribution of American silver that allowed the newly emergent Europe to buy into the dominant Asiatic trade networks, which it eventually came to dominate.

A reevaluation of the globalizing process needs to consider the circumstances under which such processes developed and whether "globalization," the integration of global commodity markets, is continuous or disjunctive with other region-making or network-forming processes. Some of these processes can be explored through the study of changing patterns in the ways material culture is represented in a native society, which provides an alternative perspective for understanding the local engagement with the European colonization, previously seen only through the lens of European chroniclers.

Material culture is important for the study of globalization and colonialism, both for understanding its present form and investigating its inception. Rather than providing mute testimonies of social change, material cultures serve as realms of social action through which social relationships are reproduced, negotiated, and transformed (Appadurai 1986). People and groups negotiate their social lives through connections linking the processes of producing, exchanging, and consuming symbolically meaningful artifacts, such as porcelain. In this article, I examine these processes in an analysis of porcelain consumption and exchange in the Philippines, before and after Spanish colonization of the archipelago. Having been part of the Asiatic trade network

Li Min is an Assistant Professor of East Asian Archaeology in the Department of Asian Languages and Culture and the Department of Anthropology at the University of California at Los Angeles. 
since the eleventh century, the Philippines played a critical role for the emergent European colonization of Southeast Asia after the late sixteenth century. Its place in the trans-Pacific navigation route and close proximity to China, Japan, and Southeast Asia, transformed the Philippines into a bridge between three worlds-East and Southeast Asia, the Americas, and Europe. My research considers how indigenous chiefly polities were ultimately entangled with processes of change unfolding at the global scale since the thirteenth century.

Since trade ceramics feature prominently in the symbolic reproduction of social relations in the chiefly societies of the Philippines, my analysis of ceramic trade seeks to answer these questions: What characterizes the structure of Asiatic trade and the nature of the colonizing enterprise at the advent of European expansion? In what ways did it differ from the "traditional" mode of trade, thus making it modern, global, or capitalistic? How did the process of colonization, and the Philippines' eventual incorporation into the global economy, change the existing pattern of ceramic trade and consumption in the southern Philippines? The answers to these questions lie in the chronological variations in ceramic assemblages and major thresholds in consumption patterns.

\section{THE GUTHE EXPEDITION AND THE GUTHE COLLECTION OF TRADE CERAMICS}

The Guthe Collection of the University of Michigan Museum of Anthropology (UMMA) is the most important collection of Philippine archaeological materials and Asian trade ceramics in the United States (Sinopoli, this volume). Despite his lack of experience with Asian materials, archaeologist Carl Guthe undertook the expedition with the "definite purpose of gathering additional data upon [sic] the commercial relations between the Filipinos and Asiatic civilizations" (Guthe 1929:79). More than 15,000 artifacts were collected from 542 discrete archaeological sites by the University of Michigan Expedition between 1922 and 1925. The collection consists of c. 8600 ceramic vessels or fragments (most date from the fourteenth to the sixteenth century), each provenienced to site and island, as well as shell ornaments, iron and copper artifacts, beads, and ornaments of semiprecious stones, glass, and gold. The majority of the Guthe Collection came from his excavation of open-field burial grounds and caves that had been used by generations of native peoples to bury their dead.

Over a thousand Chinese blue-and-white porcelain vessels and fragments dating from the fourteenth century to the seventeenth century are in the Guthe Collection. The level of information for the collection, particularly on site location and content, is extraordinary for the period in which this collection was made. Even today, it is rare to have this much detail concerning recovery locations for many, if not most, collections of Asian archaeological materials. The fact that items are provenienced to the site and island levels allows the possibility of exploring local and regional processes of sociopolitical change.

The extensive scale of the Guthe Collection, both in volume and in spatial coverage, makes a survey of broad trends possible. Although the lack of resolution within features, partly caused by the open nature of cave burials, poses a challenge for chronological control, recent excavations of shipwrecks, kiln sites, and urban settlements in East Asia, Southeast Asia, and the New World have provided good sources of comparative information (Brown 2004; Fujian Provincial Museum 1997; Ho 1988; Zeng 
2001). Such finds have made it possible to explore the initial processes of modernization or globalization in traditional societies.

The research project is experimental at two levels: first, as an attempt to scrutinize old museum collections with new research questions, and second, to explore methods of evaluating the effect of colonization in the absence of direct colonial administration. The second aspect is particularly meaningful as the impact of trade and colonization is frequently far-reaching, beyond the level of daily engagement. For native communities away from the colonial centers, the lack of diagnostic colonial items in archaeological contexts often makes it difficult to assess changes in local political and economic realms that resulted from the colonization, particularly changes at the level of daily lives and ritual sphere. My solution to this challenge is to monitor changes to the traditional trading patterns, particularly in the access to Chinese porcelain, which provides a good control of time and source.

Chinese blue-and-white porcelain dating to the centuries before and after colonization constitutes a major category of trade ceramics in the Guthe Collection of archaeological material excavated in the southern Philippines. The invention of blueand-white porcelain was itself a product of an early world encounter (Carswell 1985, 2000; Wong 1978). The discovery of underglaze blue ware in the major Tang port city of Yangzhou and on the Belitung shipwreck in Indonesia indicates that cobalt blue was introduced to China by Arabic or Persian traders in the ninth century; it was aimed at export rather than domestic markets. It was under the Mongolian Empire, however, that the production of underglaze blue was revived by Chinese and Persian artisans during the mid-fourteenth century, working at ceramic workshops in Jingdezhen using imported cobalt (Carswell 1985, 2000; Finlay 1998).

Blue-and-white porcelain was immediately available to the overseas market, adding to the inventory of celadon, bluish white, white ware, and black ware already marketed to Southeast Asia and West Asia. The export of blue-and-white porcelain from China to the expanding world market made it the dominant category of tradeware after the late fifteenth century, coinciding with the advent of voyages that manifest "forces that were drawing the continents into more encompassing relationships and would soon make the world a unified stage for human action" (Wolf 1982:24). By the seventeenth century, blue-and-white porcelain vessels are found across colonial sites in the New World and in Europe, attesting to its key role as a symbol of prestige and colonial identity (Kuwayama 1992).

Finlay argues that porcelain yields "the first and most extensive physical evidence for sustained cultural encounter on a worldwide scale, perhaps even for indications of genuinely global culture" (1998:143). Unlike other bulk trade goods, porcelain is imperishable and diagnostic to time and place of manufacture. The importance of porcelain in both domestic society and global trade makes it an ideal medium for documenting the reconfiguration of trade and local consumption resulting from the Philippines' changing role in the emerging global economy of the early modern era.

\section{CERAMIC TRADE AND THE POLITICAL DYNAMICS OF THE PROTO-HISTORIC PHILIPPINES}

Geographic fragmentation, considerable micro-environmental diversity, and low population densities set the stage for political interactions in the pre-colonial archipelago (Solheim 1964). Indigenous Philippine societies were organized into multiple 
decentralized, weakly integrated political hierarchies that underwent short-term cycles of alternating coalescence and disintegration (Junker 1999:308). Internal processes of political growth led to a greater demand for foreign trade wealth. At the same time, an influx of foreign trade wealth offered enhanced opportunities for political coalition building and further expansion of the political system (Junker 1999).

Before the advent of Spanish colonization in the mid-sixteenth century, Chinese, Indian, Arab, and Malay traders interacted with multiple trading polities of varying scale and complexity that probably had a diverse range of trade interests in the Philippines. In the thirteenth and fourteenth centuries, trade goods brought to the Philippines included glass beads, silk, iron implements, lead net sinkers, iron needles, and ceramics. According to thirteenth- to fourteenth-century Chinese trade accounts, native goods available for the foreign market included beeswax, pearls, tortoise shells, betel nuts, and local fabrics and printed textiles (Hirth and Rockhill 1966; Su 1981). The fourteenth-century Chinese traveler Wang Dayuan noted that Philippine communities consisted of over a thousand households settled alongside rivers, often presided over by chiefs (Su 1981).

Porcelain became increasingly prominent in the Asiatic trade after the thirteenth century (Fox 1959, 1967). The incorporation of trade ceramics into Philippine ritual and political contexts has been interpreted as evidence for an escalation of chiefly competition among indigenous polities (Bacus 1995, 1999; Junker 1990, 1998, 1999; Nishimura 1992). Porcelain vessels were used in ritualized feasts associated with life crises and calendrical events, which were important contexts for social reproduction and negotiation (Junker 1999:309).

Distribution varies significantly. Chinese imports dating from the thirteenth century are a significant presence in the Guthe Collection. They first peaked during the first half of fourteenth century, then peaked twice more in the late fifteenth to early sixteenth century and late sixteenth to early seventeenth century (Li and Lee 2007). Excavations in Cebu, however, yielded only sparse evidence for Song, Yuan, and Early Ming period porcelains (Nishimura 1992), while porcelain densities increased dramatically in association with the fifteenth- and sixteenth-century Late Ming trade (Nishimura 1992:655). Junker's (1999:310) study in Tanjay (Negros Oriental) revealed that the quantity of foreign porcelains in burials and settlements increased dramatically from the fourteenth century to the fifteenth and sixteenth centuries.

In addition to an increase in quantity, scholars reported changes in the quality of porcelain assemblages, suggesting that the diverse forms present prior to the fifteenth century were gradually reduced to a more narrow range of serving vessels (primarily plates and shallow bowls) by the Late Ming period. Junker (1999) interprets this as evidence for the expanding role of competitive feasting in chiefly politics and status competition. She argues that the comparatively few but heterogeneous and high-quality export wares entering the archipelago before the fifteenth century were primarily intended for a limited market of chiefs and other high-ranking elite (Junker 1999:203). In contrast, the massive influx of porcelain of varying quality from numerous competing Chinese, Annamese, and Siamese kilns in the fifteenth and sixteenth centuries may reflect the increasing importance of foreign porcelains in local Philippine political economies, with the large cargoes of homogeneous and less attractive wares intended for a growing market of lesser nobility, commoners of distinction, interior tribal leaders, and others in alliance or client relations with chiefs. 
Nishimura's (1992:661-740) quantitative study of quality decline in porcelains excavated at Cebu characterizes this pattern as a process of "homogenization." While Yuan and Early Ming porcelains were stylistically diverse and used relatively high-quality pastes and glazes, Late Ming wares were dominated by mass-produced, low-quality export porcelains from the South China kiln sites of Zhangzhou and Jingdezhen (Nishimura 1992:661). The porcelain forms are also astonishingly monotonous, with between 80 and 90 percent of the assemblages consisting of highly standardized plates and bowls (Nishimura 1992:670). Nishimura argues that political development among a relatively undiscerning group of local elite consumers increased the demand for porcelain imports and affected the organization of production at the kilns. While initially foreign imports may have been restricted to the uppermost tier of the social hierarchy, chiefs and other elites may have increased the use of porcelains, particularly lower-quality ones, as material cement for vertical patron-client ties with lesser elites and even loyal commoners as both the hierarchical complexity and the scale of alliance networks increased in the later phases of prehistoric chiefdom development.

Against this backdrop of increasing "homogenization," there is considerable spatial variability in the quality of the porcelains consumed in the Philippines in the midfifteenth to sixteenth centuries. In Cebu, comparatively high-quality porcelains are restricted almost exclusively to a single habitation locale. Using Nishimura's criteria for assessing trade porcelain quality, Junker's (1999) research on fifteenth- and sixteenth-century trade porcelains demonstrates that chiefly residences at the coastal center of Tanjay have the highest percentage of better quality, non-Swatow, blue-andwhite wares and celadon. Elite and non-elite residents at the coastal port had better access to higher-quality porcelains than upriver settlements that were likely occupied by lower status individuals who received their porcelains through alliance gifts from Tanjay chiefs. The Tanjay evidence suggests that Philippine chiefs retained the best porcelain for their own household use, for such activities as chief-sponsored feasts, even as a large quantity of the more cheaply made porcelains were required to finance expanding alliance exchanges (Junker 1999:201).

Some key questions about ceramic consumption during the fifteenth and sixteenth centuries in the Philippines remain unresolved by previous studies. On the one hand, local elite consumers are viewed as undiscerning about the quality of imported porcelain. On the other, spatial variation indicates that quality discrimination was important in articulating social distinction. An emphasis on quantity over quality in the value systems of indigenous chiefly societies does not seem to be a satisfactory explanation of this discrepancy.

Furthermore, the Middle-to-Late Ming period covered a major event in world history: the advent of European colonialism in Southeast Asia and throughout the world. This event had ramifications for trade patterns in the southern Philippines. A careful examination of the social history of this period may indicate that the trajectory of internal political development is not independent of this major threshold in global history. The link connecting the consumers in the southern Philippines with kilns in Jingdezhen and Zhangzhou is not linear. Instead, changing patterns of native consumption are closely interwoven with globalizing processes connecting Mexico, Peru, Lisbon, Zhangzhou, Manila, and Amsterdam. The seemingly continuous pattern of ceramic consumption in the Philippines may have been accounted for by different reasons before and after colonization, so the concept of "homogenization" 
needs to be scrutinized in light of this major turn of events. I begin with a brief historical overview of the changes in global dynamics and forces in the sixteenthcentury Philippines.

\section{COMPETING MARITIME POWERS IN THE EARLY COLONIAL PHILIPPINES}

Before Magellan's circumnavigation drew the Philippines into interaction with Europeans, the Philippines were already involved in multiple trading networks involving Muslims in Manila and Sulu, the trade fleets operated by Chinese maritime enterprises based in Fujian, and Japanese enterprises based in the northern Philippines. These networks also contributed to changes in diverse stages and locales of commercial transactions, manifested archaeologically through the remains of export kilns, ports, shipwrecks, and ceramic wares in and around the region (Miksic 2006). For the purpose of this article, this brief overview only covers those changes directly affecting the trade of blue-and-white porcelain in Philippines.

Islam provided a ready-made ideological link among the Muslim trading emporia that ranged from the ports of the Indian Ocean to the Sulu Islands of the Philippines. In an archipelago characterized by extreme geographic fragmentation, Muslim merchants played an important role in the porcelain trade with the indigenous populations. The Moro traders purchased goods from Chinese and Japanese traders, which were then sold farther inland ( $\operatorname{Li} 2001$ : 78). Connections with the Islamic sultanate in Brunei led to some rudimentary state formation at the centers of interisland trade, including Manila and Cebu (Majul 1973).

Freewheeling Chinese traders offered an important link to mercantile exchange with the Philippines. During the Early and Middle Ming (1368-1522), the Philippines were among the numerous destinations for the illicit trade based on the offshore islands along the Fujian and Zhejiang coasts. Some of these armed private commercial fleets consisted of hundreds of vessels and involved tens of thousands of participants (Wills 1979; Zheng 1998). Much of this private commercial activity was outlawed as piracy by the imperial government, who saw the rise of private maritime enterprise as a threat to the security and stability of the empire. Ultimately, armed conflict between government forces and illicit traders resulted in a widespread social crisis along the Chinese coast, which only served to reinforce the government's determination to prohibit private operation of overseas trade (Higgins 1981). The result was a gap in the supply of Chinese export wares into the Southeast Asian market during the Early Ming period. Overseas factories expanded in Southeast Asia to fill the market niche left by this Ming Gap (Brown 2004).

It is tempting to envision the tension between the private traders and the imperial government during the Early and Middle Ming periods as a conflict between two ideologies: an entrepreneurial spirit versus an agrarian society's conservative Confucian cosmology that despised commerce and material indulgence (Goddio 1988). A careful examination of the historical events within the empires, however, reveals that this binary view would be an oversimplification, since the tension likely resonated as factions within the Ming bureaucracy. For instance, Governor Zhu Wan's heavyhanded crackdown on Shuangyu Island (the hub of middle Ming-period international piracy) seems to have damaged the commercial interests of so many powerful players in the Ming bureaucracy that they were able to impeach him (after which he committed suicide). Archaeological evidence indicates that there was a flood of Chinese blue-and-white porcelain to the overseas market after 1488. In contrast, an account 
written by Cui Bo, a Korean scholar official who was shipwrecked on the coast of Ningbo, reveals no signs of a relaxation of the maritime ban at the level of coastal defense (Ge 1992). One can conjecture that those responsible for enforcing the maritime ban probably benefited from turning a blind eye to illicit trade under their jurisdiction.

Among the coastal ports involved in illicit trade with the Philippines, Zhangzhou in the southern province of Fujian stood out as a key player (Fig. 1). In the sixteenth century, the port of Yuegang in the Zhangzhou region flourished as the hub of illicit maritime trade. It enjoyed a reputation as the "little Suzhou and Hangzhou" (the two wealthiest cities in the Yangtze River Delta) (Zheng 1998). After the late sixteenth century, the majority of the ships setting off from Zhangzhou were destined for the Philippines, a journey of some 15 to 20 days (Li 2001:85).

The transformation of Yuegang into an international trading center promoted the development of export-oriented industry in its hinterland, especially in the production of silk and ceramics. By the early Late Ming period, the scale of Zhangzhou's gray economy was so large that Emperor Longqing (r. 1567-1572) eventually allowed private Chinese traders to export from Yuegang under the condition that they obtain export licenses and pay taxes. Since the beginning of their production at the end of the sixteenth century, the Zhangzhou products performed remarkably well in an expanded international market traditionally supplied by Jingdezhen products. While European traders favored finer quality Jingdezhen wares for their domestic market, they frequently used coarser Zhangzhou wares to pay for goods and services received from native peoples with whom they interacted around the globe (Volker 1954).

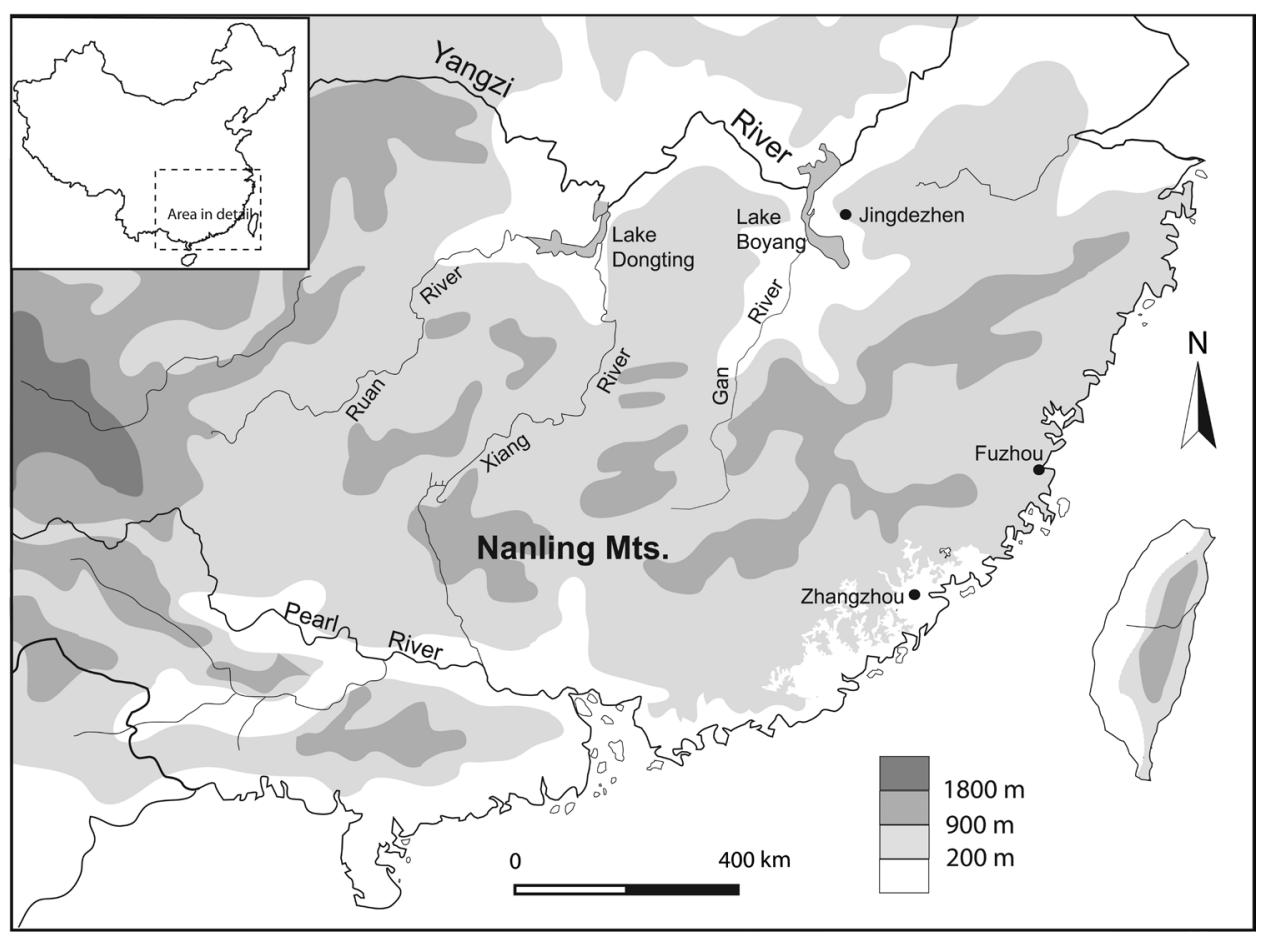

Fig. 1. Map of the Zhangzhou region. 
Consequently, the Zhangzhou porcelain is found in diverse archaeological contexts from California to South Africa (Kuwayama 1992). Unlike the fine Jingdezhen export ware, which was primarily consumed by European and Middle Eastern elites, the distribution of Zhangzhou products intersects the colonizer and the colonized, native politics and imperial aspirations, reaching remote communities where European artifacts may be rare or about which colonial accounts said little. Therefore, Zhangzhou ware represents a unique category of material culture for the study of the footprints of European colonization and early global trade.

The impetus for globalization in the late sixteenth century paradoxically lay within the Ming Empire, which was implementing fiscal reforms that increasingly relied on silver for taxation and commercial transactions. During the Wanli period (15731620), the empire experienced an unprecedented expansion of its internal market economy, accelerating the demand for silver (Von Glahn 1996:143). Against all government efforts to hold international trade at bay, an extraordinarily high silver price in China in the sixteenth century set a sequence of globalizing events in motion. In 1560, the exchange rate for gold to silver was $1: 11$ in Europe, $1: 13$ in Mexico, and 1:4 in China (Li 2001:69). Since the Ming government restricted private engagement in international trade, the high profit of bringing in cheaper silver to the Ming market became a huge financial incentive for merchants, particularly those trading with Japan, which was prohibited from both official and private trade with Ming because it supported international piracy in East Asia. European fleets (first the Portuguese and later the Dutch) also filled the role of international broker between Asiatic countries, particularly between China and silver-rich Japan. As I will discuss below, when cheaper silver from the New World became available through Manila, Asiatic merchant fleets sought it with intense interest, effectively transforming the traditional framework of Asiatic trade by adding to it a trans-Pacific dimension (Wills 1998).

While Magellan claimed Spanish sovereignty over the Philippines as early as 1522 , effective occupation of the islands was not possible until 1565, when Andrés de Urdaneta discovered a feasible eastward route across the Pacific. Circumventing the unfavorable winds and currents that had prevented earlier explorers from making the return voyage to the Spanish New World, Andrés de Urdaneta's fleet sailed northward into the Japan current, eastward along the fortieth parallel, and southward with the Alaska current, skirting the California coast to Acapulco (Kuwayama 2002). The discovery of a feasible return route across the Pacific offered Spain a back door to the lucrative Asian trade that had been denied by the Treaty of Tordesillas (1494), which granted Portugal exclusive rights to the eastern hemisphere (Cushner 1971:10).

The next milestone in Spanish colonization of the Philippines was the conquest of Manila in 1571, providing the Spanish access to the traditional Asiatic trade network. Although the Spanish avoided direct trade with China, the extraordinarily high price of silver in the Chinese market generated incentives for Chinese and Portuguese merchant ships to trade with the Spanish in the Philippines. Therefore, possession of American silver mines brought Spain into the Asian market without having to engage in the intricate interisland barter system as the Portuguese did. The inauguration of the Manila Galleon brought the commodities of Asia, the Americas, and Europe into global circulation. This was a defining moment for the beginning of early globalization.

The flow of wealth between the New World and the Philippines was carried out by the Manila Galleons. By 1573, ocean-worthy galleons regularly traversed the Pa- 
cific from Manila to Acapulco, where cargos were unloaded onto mule trains bound for Veracruz on the Gulf of Mexico (Cushner 1971; Kuwayama 1992; Schurz 1985). From there they were loaded onto Spanish ships headed for Seville. Most of the transPacific shipments of porcelain, silk, cotton from India, and other precious items, however, were destined for the Spanish viceroyalties in the New World. On return voyages, these galleons were loaded with New World silver, which was used to purchase Chinese and Indian goods in the Philippines. Scholars have various estimates of the portion of American silver shipped across the Pacific. Some estimate that onequarter of the total silver flow went to Asia, much of it as contraband (Frank 1998).

After the advent of the galleon trade, Manila became the hub of a trade network that drew the Chinese trading enterprises into the Philippines' orbit and created a commercial circuit in which Chinese goods were exchanged for New World silver (Wolf 1982). Flynn and Giráldez (2004) have argued that globalization began when the Old World became connected directly with the Americas in 1571 via Manila. During the first 10 years of the seventeenth century, some 90 junks from South China called each year at the great seaport of the Philippine archipelago, and Manila's Chinese community grew to over 30,000 (Goddio 1988:128).

Commercial fleets involved in this trade were organized under an increasingly centralized and autonomous political leadership on the Chinese coast. During the decades of the Ming-Qing transition, this maritime polity achieved significant political autonomy as well as commercial monopoly under the leadership of the Zheng lineage, particularly Zheng Zhilong (aka Nicolas lquan Gaspard, 1604-1661) and Zheng Chenggong (aka Koxinga, 1624-1662) in the seventeenth century. From translators, collaborators, and brokers in the trade with Europeans, they became commercial magnates and sovereigns over a multinational empire, which, depending on circumstances, competed or collaborated with European trading companies to further its own ends (Andrade 2004).

Precious metal available from the Philippines made the archipelago a target for these private maritime enterprises on the edge of the Ming Empire. In 1574, Lin Feng's (Li-ma-hong in Spanish documents) huge fleet failed in an attempt to take the Philippines from the Spanish. In 1662, Zheng Chenggong plotted to take the Philippines from the Spanish after driving the Dutch out of Taiwan (Zheng 1998). Even traditional empires cannot remain aloof to the promise of newly emerged wealth. In 1593, Japanese regent Toyotomi Hideyoshi threatened to annex the Philippines, causing much military preparation by Spanish defense forces (Goddio 1988:216). In 1602, the Wanli emperor was persuaded to send the Ming navy to the Philippines to investigate rumors of gold mountains. Such attempts at controlling the Philippines inevitably led to crisis and bloodshed and forced the colonial authority to seek military service from the indigenous population, a process that had the potential to alter political interactions on the archipelago.

Two factors negatively affected the role of the Philippines in international trade and caused its decline: first, Spanish restrictions on galleon trade, and later Dutch attempts to cut the trade route connecting the Philippines with China and Japan. The addition of the Philippines to the Spanish Empire challenged Spain's capacity to keep the New World market to itself. The flood of Asian imports resulted in a drain on American silver destined for the Spanish crown. Seville and Cadiz strove to regulate the transshipment of Asian goods into Central and South America to protect their investments in the American market. Spain, whose first explorers sailed in search of goods such as Asian textiles that the Philippines were partially able to supply, found itself in 
the unique position of restricting their importation (Cushner 1971:128). A series of strict regulations were put in place in the early 1590s to govern the movement of the galleons between Manila and New Spain. This regulation, called the permiso, reduced the trade to two galleons a year, each with a cargo capacity of less than three hundred tons, and set a ceiling on the market value of the merchandise they could carry. Moreover, unrestricted shipping by New World merchants was forbidden and only residents of the Philippines were permitted to ship goods. Spanish restrictions on American-Asiatic trade were further undermined by widespread smuggling onboard the galleons.

Dutch attempts to push Spanish traders out of Asia proved more detrimental to the participation of the Philippines in global trade than Spain's restrictions. As a rival commercial interest to the Iberians after 1600, the Dutch commercial enterprise attempted to seize a monopoly over the lucrative China and Japan trade by raiding Chinese and Portuguese commercial fleets on their way to the Philippine market, seizing Manila Galleons, attacking shipyards, and imposing armed embargoes on Chinese and Philippine ports. Yuegang was a major target of Dutch attack, resulting in huge losses for Chinese traders and causing the rapid decline of the port city (Li 2001). In response, the Chinese commercial fleet was forced to reduce its Philippine trade and turn instead to the Dutch in Taiwan.

How did the diverse communities of the Philippine archipelago respond to these dramatic changes? Unlike the American Indians, the people of the Philippines had probably developed some resistance to the diseases that had arisen in the great urban centers of the eastern hemisphere, such as smallpox and plague, and did not suffer high mortality when the Spanish arrived. The Spanish governed the Philippines from the Viceroyalty of New Spain in Mexico, following the blueprint of empire building they had developed in the New World. To expand its territory and establish colonial control, Spanish authorities implemented the encomienda system, which gave grants of land and labor to deserving Spanish colonists.

For territories beyond the immediate hinterland of Manila and Cebu, however, the situation was very different from the New World colonies. Extreme social fragmentation presented the Spanish with formidable physical obstacles to repeating their success in conquest and colonization around the New World. They were unprepared for the difficulties of securing widely scattered islands controlled by many continually battling chiefs who seem to have had no permanent political hierarchies and spoke mutually unintelligible languages (Junker 1999:305). Furthermore, they were puzzled by their inability to convert "blood alliances" and tributary relations established with regional paramount chiefs into sovereignty over local headmen (Junker 1999:307). In addition, the profit the Spanish could earn from brokering the galleon trade was so high that there were few incentives for developing agriculture, mining, or other industries in the Philippines. Political and economic development were neglected in the Philippines, as the Spanish focus remained on seaports and international maritime commerce.

This neglect of the interior does not, however, mean that relations were peaceful between the colonists and local communities. The Spanish established military, administrative, and religious authority over the Philippines, often at the expense of indigenous political development and emerging Islamic statehood of the earlier period. Paramount chiefs and local sultans saw the rapid erosion of their influence and sources of wealth and prestige goods after they lost major trade ports to the Spanish. 
Numerous rebellions were staged in collaboration with political powers beyond the archipelago, sometimes with Islamic states and sometimes with Spain's European rivals (Majul 1973). A dazzling array of actors was involved in colonizing the Philippines. As a result, the political dynamics on the archipelago was more complex than the dichotomy between Europeans and natives would suggest. Opportunities often emerged for the outnumbered Spanish colonists to solicit military alliances from the native leadership against any imminent threat from its Asiatic or European rivals. This allowed the agency of native elite to be articulated into the broad arena of political negotiation, which was shaping the colonial society.

\section{THE GUTHE COLLECTION OF BLUE-AND-WHITE PORCELAIN}

\section{Patterns}

The contrast in blue-and-white porcelain patterns before and after the Spanish colonized the Philippines in the late sixteenth century serves to monitor changing trade relations under known historical circumstances. My research focuses on the cave (C) and burial (B) sites described in Guthe's field catalog. These were not the only types of sites that Guthe excavated, but they collectively contributed the largest share of the imported ceramics in the collection and had better provenience records. Therefore, they are a reliable representation of the overall universe of the blue-and-white porcelain from the southern Philippines. In some instances, Guthe even noted the association of locales where he collected potsherds with settlements or other sites such as the "remains of Moros watch tower" or a "Spanish garrison." These notes shed light on the context of sites in the historical landscape.

My analysis entails the following steps: (1) date blue-and-white porcelain specimens; (2) identify the region of production; (3) determine the quality of each specimen; and (4) quantitatively document changing patterns in quality and region of production across major phases of the Ming period for caves and burial sites.

Several variables were recorded for each vessel. Generally, the catalog number designates a single specimen. In the Guthe Collection, however, a group of potsherds may share the same number. If they are from a single item, I have counted them as one; otherwise, I assign multiple counts. In addition, I recorded my photo numbers (usually a specimen has two or three photos-front, back, and close up), and information on morphological type, production region, design attributes, and quality grade. A total of 720 vessels from 78 sites were examined.

\section{Dating Blue-and-White Porcelain}

I dated each diagnostic specimen based on the paste, glaze, and stylistic characteristics by comparison to published reference collections and site reports (i.e., Fujian Provincial Museum 1997; Harrison-Hall 2001; He 1996; Ho 1988; Scott and Kerr 1994; Zeng 2001), through visits to kiln sites and museums in China, and through consultations with archaeologists who have excavated kiln sites and shipwrecks. I gave priority to shipwrecks, as each contains a large assemblage of ceramics manufactured over a relatively short time span, thus giving a more precise indication for dating.

For the purpose of this research, blue-and-white vessels are attributed to several major periods: Yuan (1271-1368), Early Ming (1368-1464), Middle Ming (14651522), Late Ming (1522-1644), and the Transitional Period (1644-1683). Yuan, Early 
Ming, and Middle Ming pre-date the Spanish arrival in the Philippines, while Late Ming and the Transitional Period date to the period of colonization.

There are fewer than a dozen Yuan blue-and-white porcelain specimens in the entire Guthe Collection, with one in the study sample. This, however, does not reflect the actual Yuan trade volume, as blue-and-white ware represents only a tiny fraction of the enormous volume of porcelain trade during the thirteenth and fourteenth centuries (Li and Lee 2007). The majority of the Yuan ceramic exports were celadon wares from the Longquan kilns.

Early Ming ceramics are also rare in the Philippines, which is consistent with the general pattern for this period in Southeast Asia. In her dissertation study of shipwreck cargo from Southeast Asia, Brown (2004) has attributed this century-long gap to the effect of the Ming government ban on maritime trade as a measure for curbing piracy.

The majority of Guthe blue-and-white porcelain specimens fall into two major blocks of time: the Middle Ming and the Late Ming. Based on style, dating of some of the more diagnostic Ming porcelains can be further refined into major reigns: Hongzhi (late fifteenth century), Zhengde (first quarter of the sixteenth century), Jiajing (mid-sixteenth century), Wanli (last quarter of the sixteenth century to first quarter of the seventeenth century), and Chongzhen (second quarter of the seventeenth century). Since there was a major decline in the production and export of celadon and other wares after the Early Ming period, the quantity of blue-and-white can be taken as a reliable indication of the overall pattern in ceramic trade. Shipwrecks show that the end of the Ming Gap (1368-1487) was marked with a flood of Hongzhi period blue-and-white wares from Jingdezhen (Brown 2004; Goddio 2002), which is consistent with the pattern in the Guthe Collection.

European involvement in the trade in Chinese porcelain started in the early sixteenth century, marked by the presence of Zhengde period ceramics in Portuguese settlements on the South China Sea, such as Shangchuan Island in Guangdong (Huang and Huang 2007). In the Philippines, however, the European intervention in Asiatic trade did not begin until after the Spanish colonization in the last quarter of the sixteenth century; thus it primarily manifested in the Late Ming and Transitional periods.

Stretching from the Late Ming to the Early Qing periods, the Transitional Period saw the domination of the porcelain trade by the Zheng family's semi-autonomous maritime enterprise (Andrade 2004; Kilburn 1981; Little 1983). Blue-and-white porcelain exported during the earlier part of the period was either produced in Fujian by the kilns associated with the Zheng family or manufactured in Jingdezhen on Dutch orders, often through the Zheng enterprise. While some stylistic attributes were specific to the Transitional Period, such as the single-leaf design, other motifs persisted from the Late Ming period. Since it is a continuation of the Late Ming trade pattern, I include the Transitional Period in the post-contact category for analysis.

The Transitional Period was followed by another gap in blue-and-white porcelain in the Guthe Collection during the Early Qing period. This may have been caused by the Qing government's policy of compulsory evacuation of coastal populations to punish them for supporting Zheng Chenggong's maritime forces (which had resisted the Manchu troops after the fall of the Ming Empire). The forced evacuation of coastal populations and a new ban on maritime trade effectively shut down Zhangzhou production. Meanwhile, warfare leading to the consolidation of the Qing Empire devastated the ceramic industry at Jingdezhen. Dutch orders for porcelain went to Arita in Japan until the trade ban was lifted in 1683 and the Jingdezhen ceramic 
industry was revitalized. This gap in the Guthe Collection of Chinese exports is the cutoff point for this research project.

\section{Sourcing Blue-and-White Porcelain}

Preliminary identification of the region of production was based on observations of technical and stylistic attributes from published sources, specimens from dated archaeological contexts in Chinese museums, and field research at key kiln sites in China, primarily coastal kilns of Fujian and Zhejiang. Two comprehensive comparative collections visited for source comparison were the archaeological potsherd collection at the Palace Museum in Beijing and the potsherd collection of Zhejiang Provincial Museum in Hangzhou, Zhejiang. To assure identification, digital images of every specimen in the collection were examined with Li Jian'an, a leading specialist in archaeological ceramics at the Fujian Provincial Museum and director of the excavation of Zhangzhou kilns.

Admittedly, sourcing the ceramics based on visual observation is a challenging task, particularly as several kilns copied the same designs and forms to compete internationally. Therefore, only broad categories (i.e., Jingdezhen, Zhangzhou, Fujian, and unknown origin) were used in my study. Jingdezhen, the nexus of the Chinese ceramic industry in Jiangxi, shifted its primary production from bluish white ware to blue-and-white by the end of the fourteenth century (Medley 1993). By the Middle Ming period, blue-and-white porcelain from Jingdezhen already dominated the domestic and international market.

In the Late Ming period, scarcity in raw materials and rising tensions between government inspectors and potters eventually resulted in the 1602 potters' revolt, leading to the destruction of the imperial workshops. Export production expanded rapidly, however, as seen by the widespread distribution of Kraak porcelain in European and colonial contexts, as well as on shipwrecks. Kraak ware is blue-and-white porcelain with a brittle-glazed body and coarse base with radiating chatter marks. Decorative fields are often divided into panels. Common motifs include naturalistic plants, birds, insects, and animals; human figures are also present. Rinaldi (1989:68) identifies the following characteristics of Kraak ware: thinness and lightness are principal features; retained impurities produce pitting and small imperfections; glaze has a bluish tinge and, due to a slight incompatibility with body materials, has a tendency to flake off on rims; rims are flat, everted, or straight and foliated lips predominate; foot rims in dishes have rounded edges and are often undercut, in bowls they are thin and straight, the edge is always unglazed and it is common to find coarse sand adhering around the foot-ring (Fig. 2).

Kraak was primarily a Jingdezhen production for the Middle East and European market. Since export generated higher profits than the domestic market, the quality of Kraak ware is generally higher than that of common wares distributed in the domestic market (Rinaldi 1989). The production may have centered in the Guanyinge area in the modern city of Jingdezhen. However, no academic excavation has been conducted to confirm the information revealed by occasional presence of wasters.

Responding closely to the dynamics of global trade, in which a new market was created with the expansion of European colonial adventure, ceramic production operated by multinational maritime profiteers rose rapidly in the hinterland of Zhangzhou. Completely export driven, these factories made enormous quantities of generally 


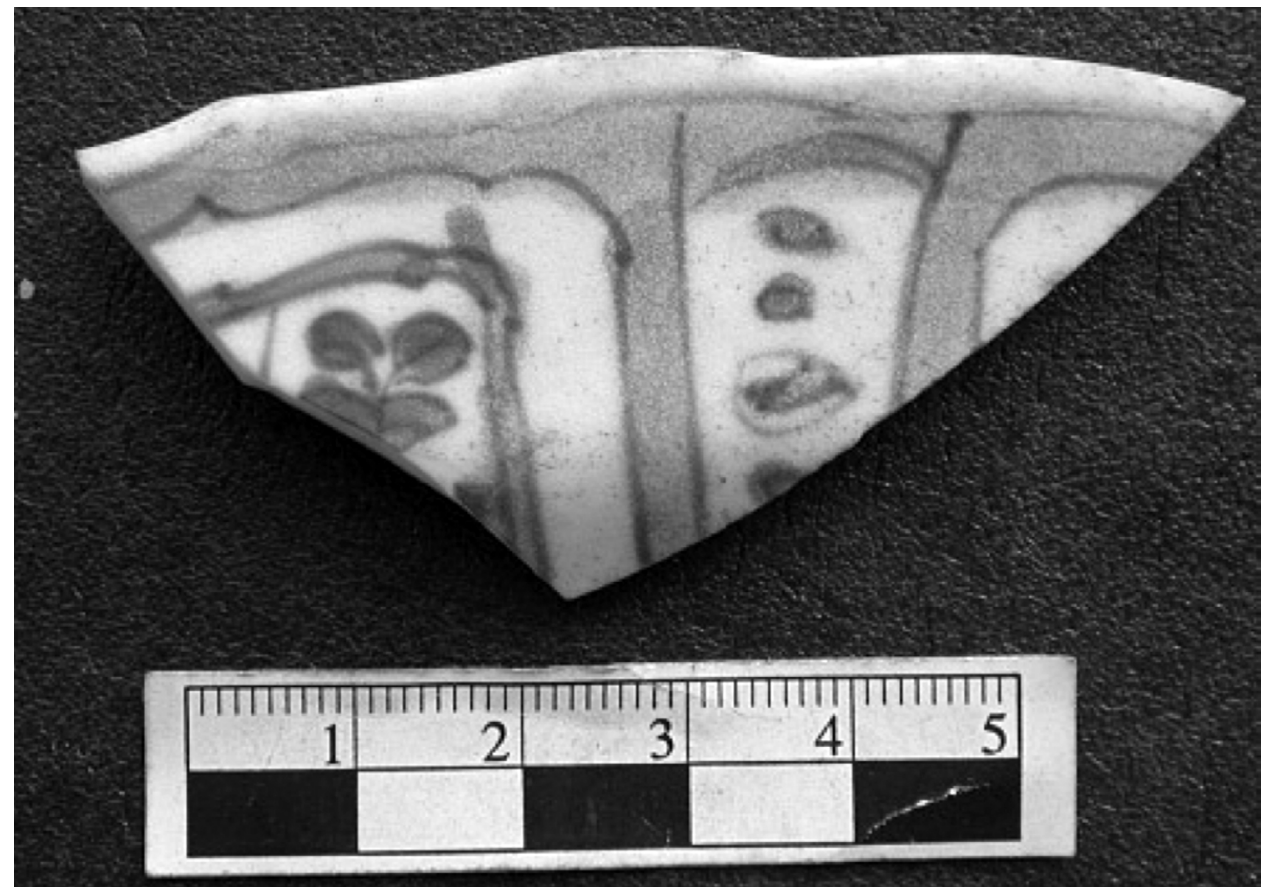

Fig. 2. Rim fragment of a Jingdezhen Kraak porcelain with panel design (B15-6); UMMA 18458, photo no. 8393 (photo by Li Min).

inferior quality copies of Jingdezhen wares; these were called Swatow wares before their production sites were identified (Harrisson 1979). Although the Zhangzhou workshops copied Jingdezhen products, they did not necessarily copy their production techniques. Instead, the Zhangzhou potters modified local technological traditions, which favored large volume firing over quality control, to facilitate mass production. For instance, Zhangzhou production employed large step-chamber kilns that can fire significantly more vessels than the smaller gourd-shaped kilns used in contemporaneous Jingdezhen production (Figs. 3, 4). Since the mid-1990s, dozens of such production sites have been identified in the Pinghe region, which lies upstream from Yuegang, and they are collectively called the Zhangzhou kilns (Fujian Provincial Museum 1997). Although we may now confidently attribute many Late Ming specimens to the Zhangzhou region, and even specific kilns in the Wuzhai Township of Pinghe County (Fig. 5), there still remain some unidentifiable fragments, which were likely produced in as yet undocumented kilns in other regions of Fujian and the adjacent Guangdong province. A similar problem also exists for the Jingdezhen kilns, where research on commercial kilns falls far behind the research on imperial kilns. Therefore, my research only distinguishes between the Jingdezhen and Zhangzhou production regions, which are well studied and had the largest market share.

The Zhangzhou kilns produced a type of gray, buff, or white porcelain with a thick, syrupy, and frequently crackled glaze. There is a very limited variety of morphological types, primarily bowls, dishes, and jars, all with thick bodies. The clay itself is either dense and gray, or loose and orange, without the high translucence of the Jingdezhen clay. Harrisson (1979) places the decoration into two broadly defined groups. Decoration with the "Simple Style" is characterized by the use of relatively 


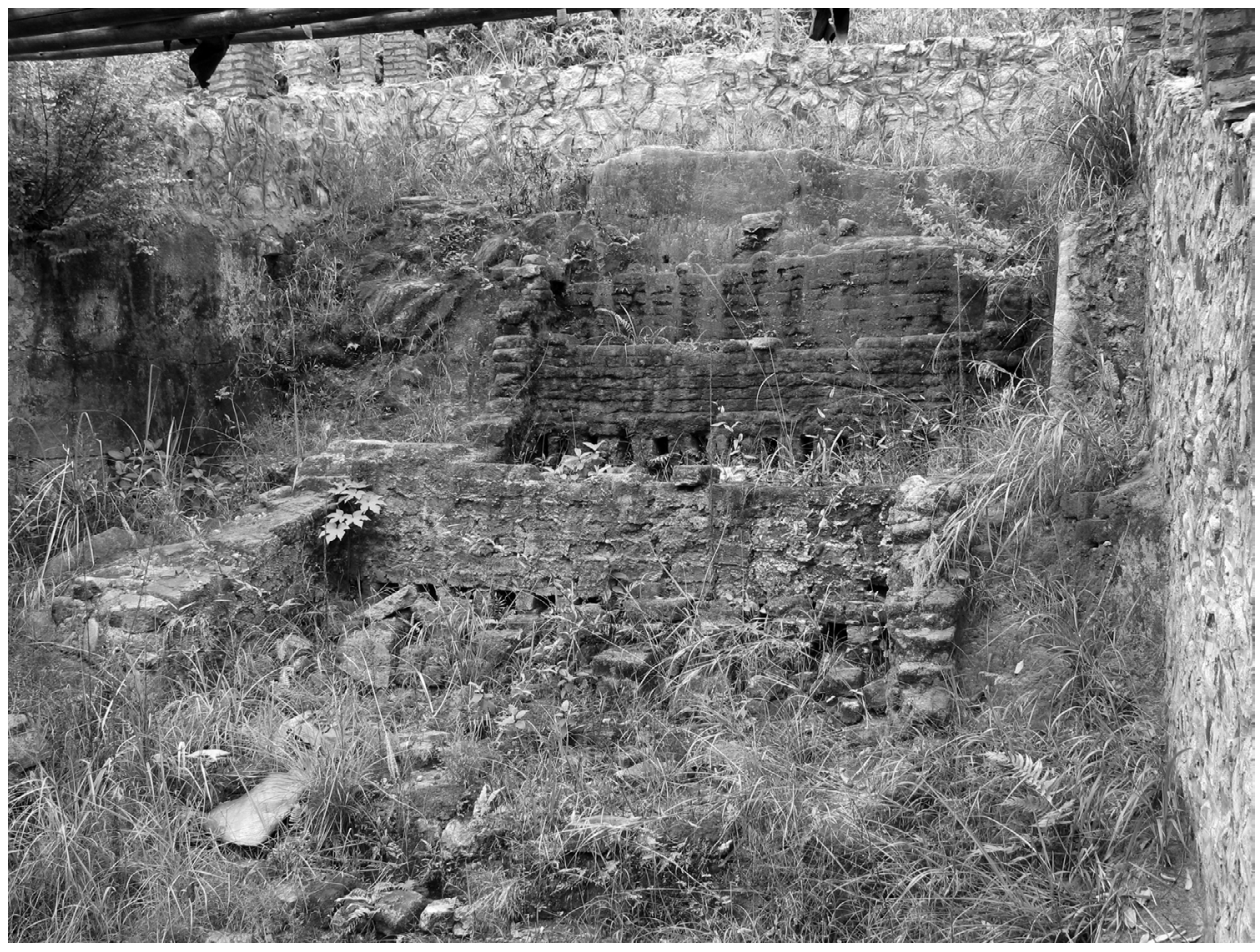

Fig. 3. One of the excavated kilns at Wuzhai Township, Pinghe County, Zhangzhou (photo by Li Min).

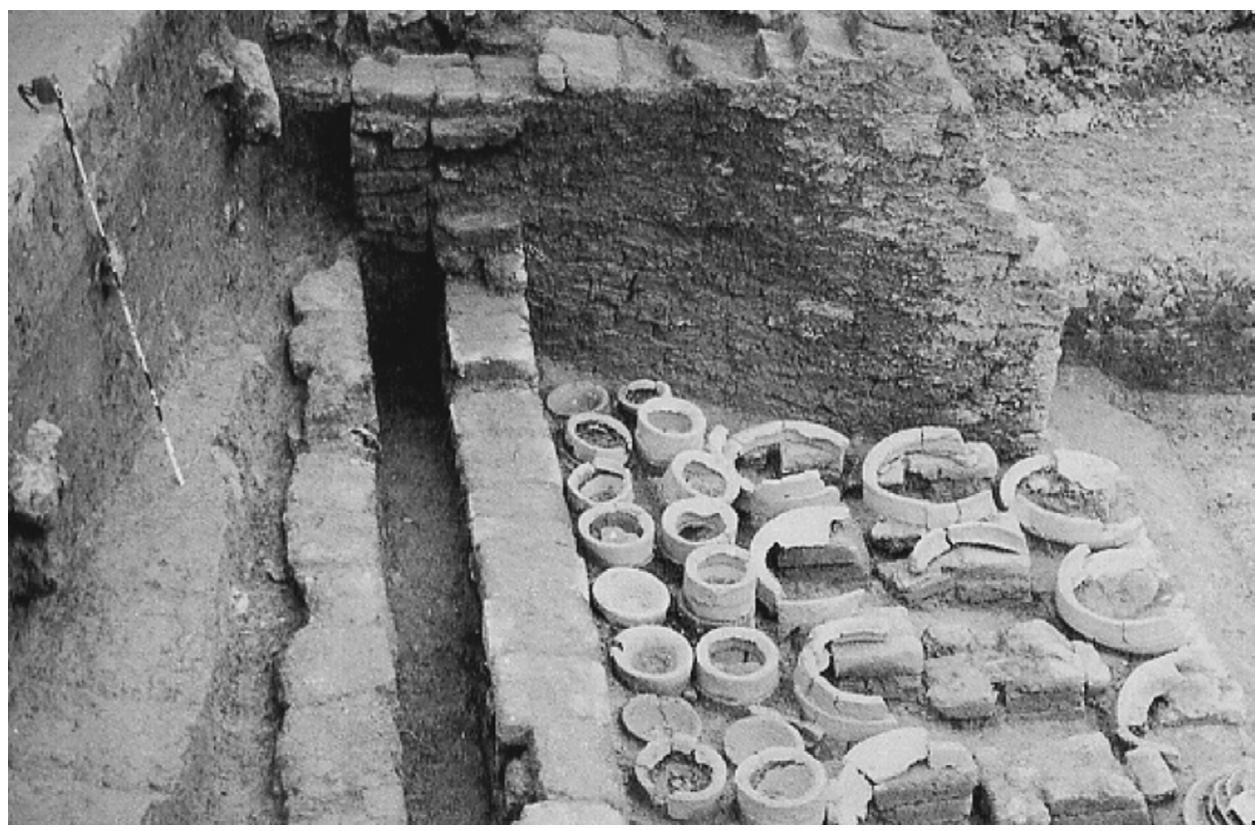

Fig. 4. The arrangement of saggers inside a step-chamber kiln at Dalong, Wuzhai Township, Pinghe County (photo provided by Li Jian'an). 


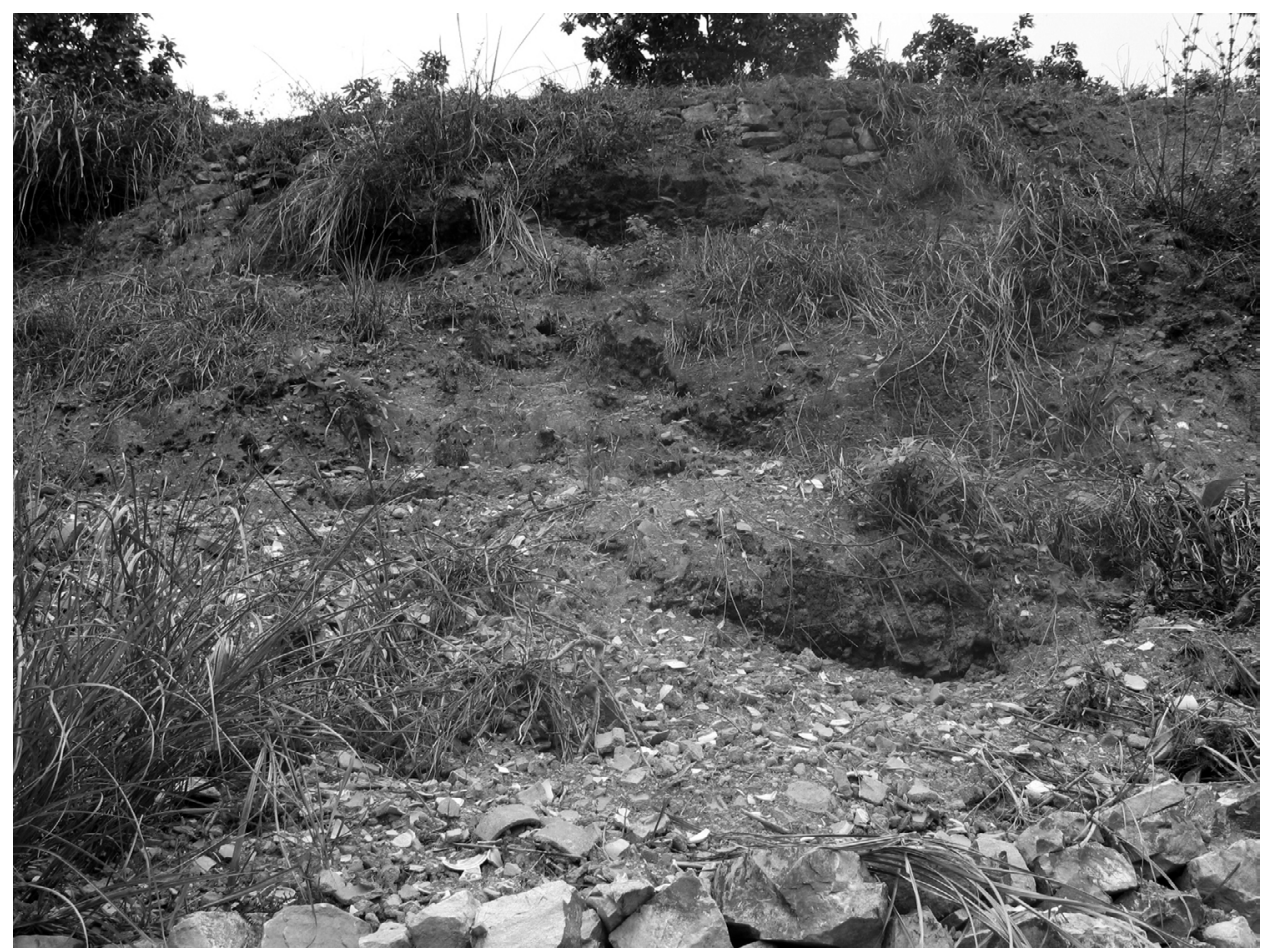

Fig. 5. Scatters of kiln wasters at Erlong site, Wuzhai Township, Pinghe County, Zhangzhou (photo by Li Min).

broad brushstrokes in depiction of floral patterns, mythical animals, birds, and human figures (Fig. 6).

The "Complex Style" depicts conventional landscapes and symbolic animals, but the scale of detail is relatively small. Some have complex themes, including depicting human beings involved in navigation, exploration, and international trade (Harrisson 1979: 41). The most common pattern depicts ducks in a lotus pond or deer in a forest park. Sometimes, the decoration involves the use of a polychromatic palette in addition to blue. The "Complex Style" seems to draw inspiration from Kraak wares from Jingdezhen, but was executed in a more casual, folk style (Fig. 7). Specimens from the Dalong and Erlong kiln sites in Wuzhai reveal that both types were made simultaneously at the same place.

In comparison with Jingdezhen production, Zhangzhou wares have several distinctive technical attributes ( $\mathrm{Li} 2005)$ :

1. Zhangzhou potters frequently applied the glaze after shaping the foot-ring, thus leaving the entire foot-ring covered with glaze, increasing the risk of adhering to sand on the bottom of the sagger during firing. In contrast, Jingdezhen potters applied the glaze first and then scraped the base of the foot-ring; they often scraped an additional sloping surface on the exterior of the foot-ring.

2. While Zhangzhou potters usually placed the dishes upside-down and poured the glaze over the vessel on a fast turning wheel, resulting in an uneven glaze and splashing marks, Jingdezhen potters dipped their dishes and bowls up to the rim to apply an even glaze over the exterior surface. 


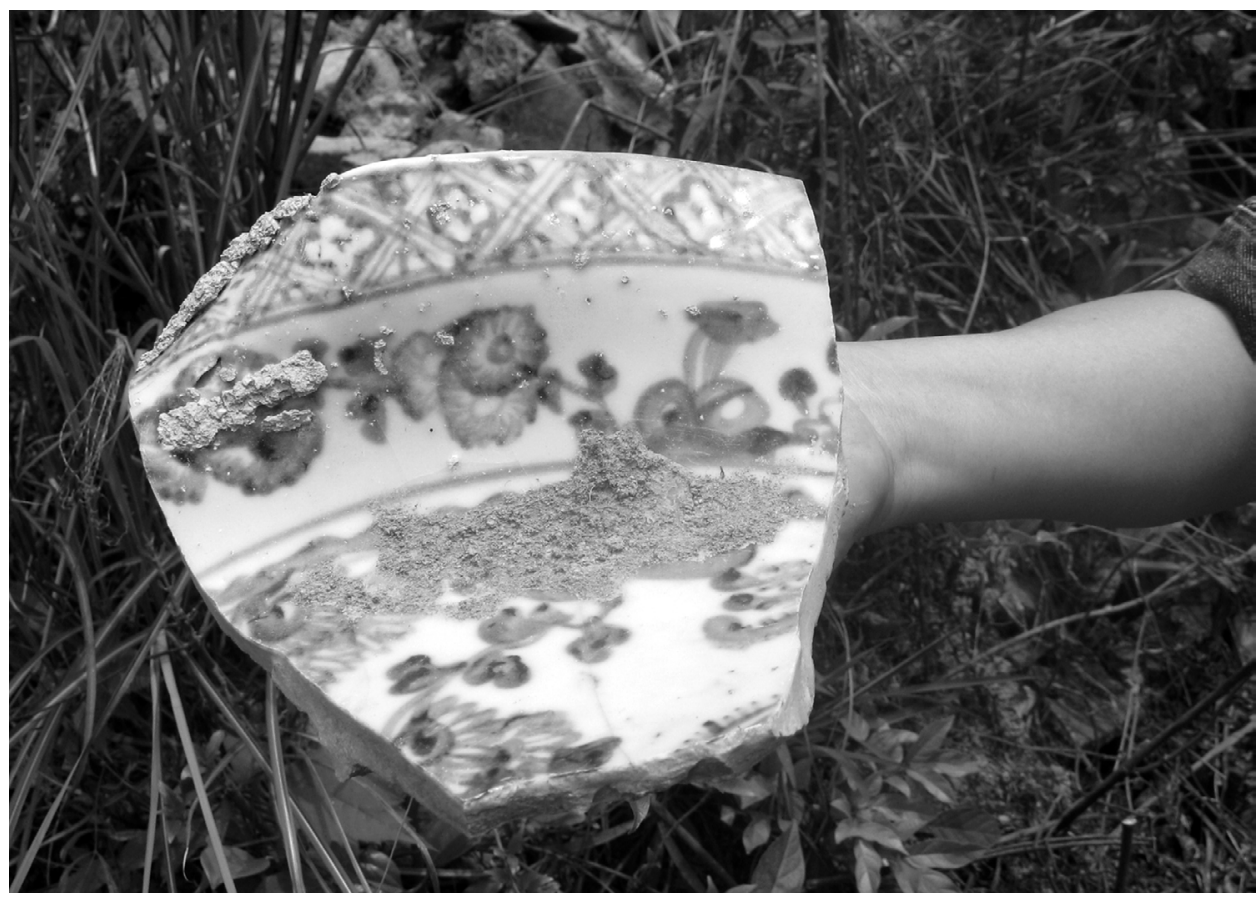

Fig. 6. Blue-and-white porcelain of "Simple Style" design at Erlong site, Pinghe County, Zhangzhou (photo by Li Min).

3. When loading the dishes, the Jingdezhen potters implemented multiple measures to prevent the sand on the flat bottom of the sagger from adhering to the vessel, including placing a stand under each vessel to prevent contact with the floor (Li 2005). The Zhangzhou potters, by contrast, reduced kiln furnishings at the expense of clean foot-rings; they usually placed each vessel directly on a thick layer of coarse sand, which then adhered to its bottom (seen in the dark layer underneath each plate in Figure 8).

There are variations among different kiln sites and production phases, but the majority of Zhangzhou products bear these attributes.

There was also small-scale production of blue-and-white porcelain at other regions in Fujian, such as Anxi and Dehua, during the Late Ming period, but we lack the precise information needed to make a positive identification (Chen 1999; Ho 1988; Tan 1997; Zhang 1989). I place specimens from this category under the general label of "Fujian." Those without enough stylistic attributes to place even in this broad category are termed "unknown."

While the majority of Zhangzhou copies have a distinctive folk style in their execution of the complex decoration, recent research at the kilns reveals that some Zhangzhou copies are of rather fine quality. Therefore, high quality Fujian production may also be classified as Kraak ware due to its shared attributes in design and quality. This also means exceptionally fine Zhangzhou specimens may be attributed to Jingdezhen. Thus, a careful discrimination on the basis of technical characteristics rather than quality alone is necessitated. 


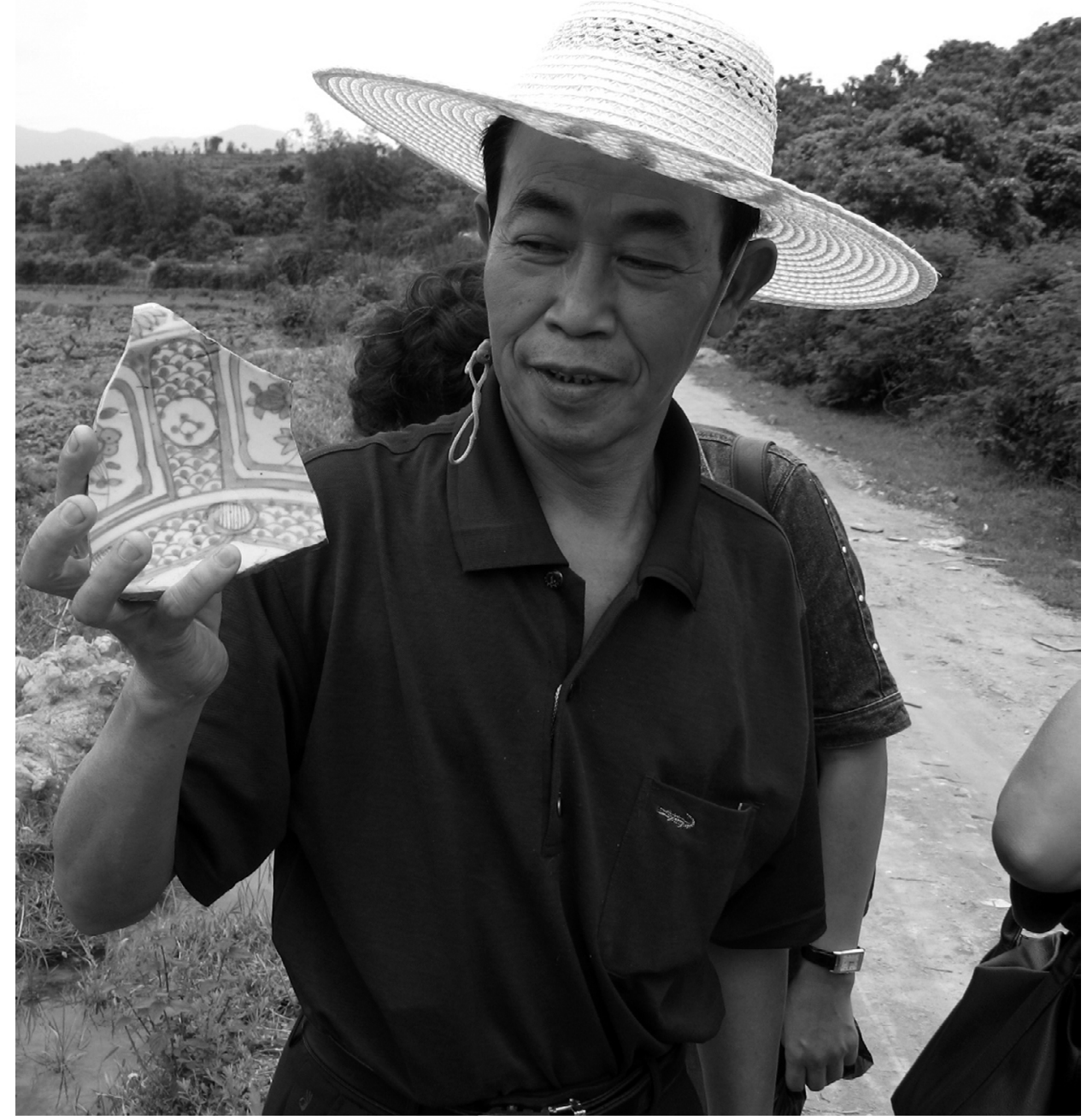

Fig. 7. Director Zhu Gaojian of the Pinghe County Museum displaying a fragment of Kraak style blueand-white porcelain found at the Dalong site, Pinghe County, Zhangzhou (photo by Li Min).

\section{Determining the Quality of Blue-and-White Porcelain}

Although comparing quality across different periods and production sites is challenging, classifying the porcelains into five types captures broad trends in porcelain consumption in the local society. I modified Nishimura's (1992) four-tier quality grading system by adding a fifth tier for what would be considered defective products generally not put on the market.

Type I: Glaze is clear and glassy. The body is of fine-grain kaolin clay, so this porcelain has a smooth texture and is very white. Construction is usually very precise and even (Fig. 9).

Type II: Glaze is less clear with a slightly white tinge and syrupy, giving the impression of a heavy glaze. The paste represents a type of grayish porcelaineous stoneware. 


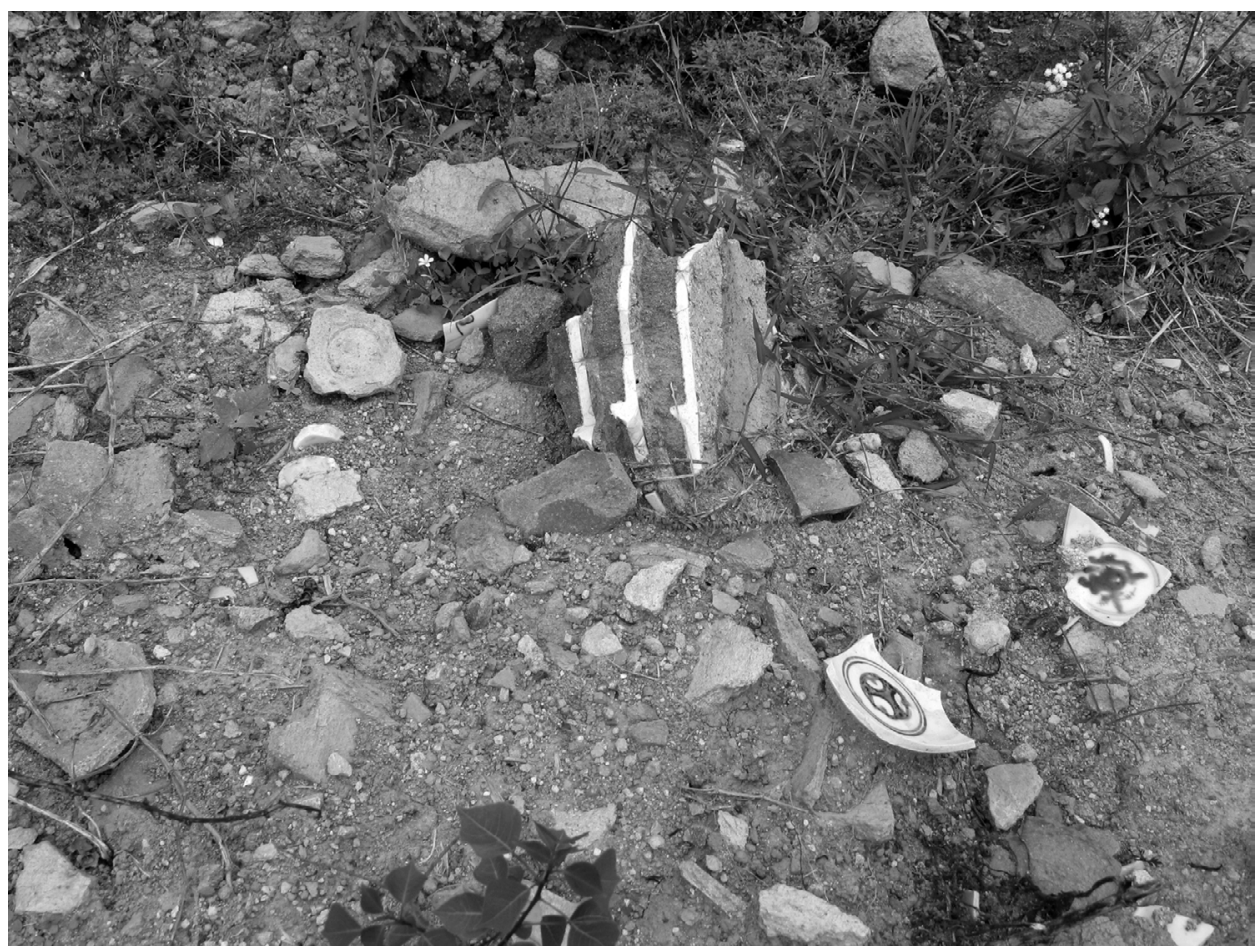

Fig. 8. Kiln wasters at the Erlong site, Pinghe County, showing dishes set in a thick layer of dark sand (photo by Li Min).

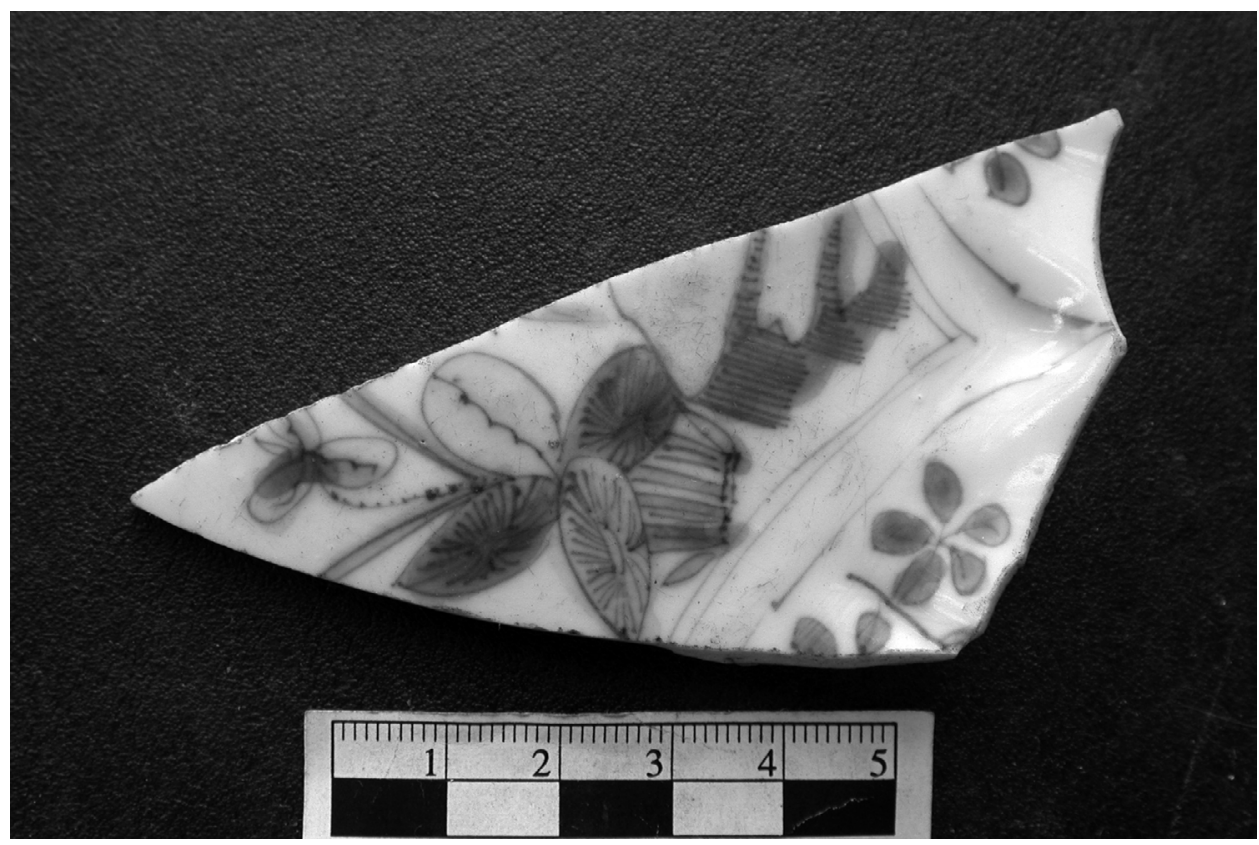

Fig. 9. Example of a Type 1 porcelain, produced at Jingdezhen (B15-5, UMMA 18457, photo no. 7894) (photo by Li Min). 
Construction is less refined, but retains a high level of precision in comparison to mass-produced wares.

Type III: Glaze is not clear at all, but milky and syrupy, including many bubbles. The clay is a finer light gray stoneware. Nishimura (1992) calculates that the Type III glaze dominates the blue-and-white ware assemblage in all Cebu localities through all periods.

Type IV: Glaze is poor, uneven, and frequently crackled. It is milkier, with much larger bubbles, and more sticky and syrupy. Although the general characteristics of this type of glaze are similar to those of Type III, the quality is worse. It is thus different from Type III in degree, not kind. Construction is uneven and uses a stoneware paste made of grainy clay that is coarse in texture and gray to dark gray in color.

Type V: Pieces of substandard or defective quality that were generally not intended for the market. The surface is frequently marred by pinholes or cracks and has a tendency to flake off. The clay is incompact, coarse, and lacks purity (Fig. 10).

Any general quality grade based on technical sophistication is inevitably confronted by questions of aesthetics and taste of different cultures. Coarse porcelain is not universally regarded as less valuable than finer ones. For example, in Japan, a major importer of the Zhangzhou ceramics, the simplicity and perceived free spirit of these mass-produced goods had such an appeal that they were sometimes regarded as more desirable than fine porcelain. Upon examining the entire photo inventory of the blue-

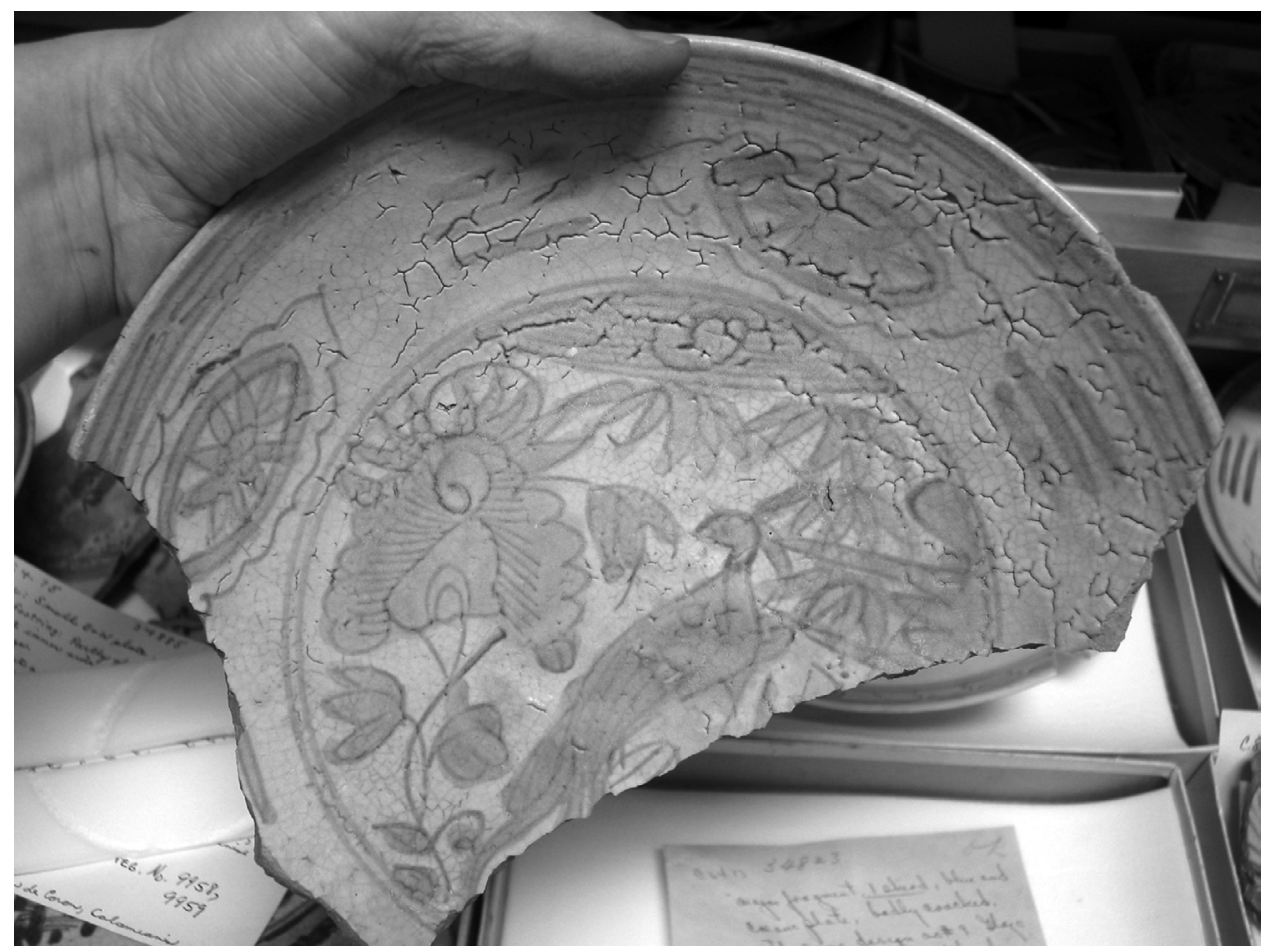

Fig. 10. Example of a Type V quality blue-and-white ware produced at Zhangzhou (B64-I3, photo no. 1789) (photo by Li Min). 
and-white porcelain in the Guthe Collection, Li Jian'an (pers. commun. August 30, 2005) observed that there is higher ratio of defective pieces among the Zhangzhou products in the Guthe Collection than those he saw in Japanese urban excavations. This suggests that a distinction was made between quality and style in Japan, a major market for Zhangzhou ware.

Native societies of the Philippines desired ceramics that could be rung (Fox 1967 : 48). Ritual foods were placed in a bowl or plate, held above the head by a medium, and tapped five or seven times to call the spirits of relatives and deities to partake in the offerings. True porcelain dishes were prized because the deities could easily hear the clear musical tones (Fox 1967:48). Since most specimens are in small fragments, I could not include this criterion in my grading. However, my observations of complete specimens suggest that their capacity to produce a ringing tone is positively correlated to the density of the clay paste and the firing quality, which would be consistent with the grading system used here.

\section{ANALYSIS OF PATTERNS IN BLUE-AND-WHITE PORCELAIN TRADE}

The social significance of any shift in ceramic consumption in a native society is best appreciated by looking at the quality variation of its imports. Both Zhangzhou and Jingdezhen produced wares in a wide range of quality.

\section{Cave Sites}

The quality distribution of Middle and Late Ming (including the Transitional Period) blue-and-white porcelain from cave sites is summarized in Table 1. Numbers represent the quantity of potsherds for each quality grade and percentage represents the proportion of each quality grade during each period. Detailed counts of potsherds in every quality grade by each cave are presented in Appendix I.

A chi-square test reveals a significant association between time period and vessel qualities, $\mathrm{x}^{2}=61.099, \mathrm{df}=4, \mathrm{p}<0.001$. Therefore, the difference in quality distribution between the two periods is significant. Table 1 indicates that approximately half (52\%) of the vessels in caves during the Middle Ming (MM) period were quality Type III, and about 21 percent and 22 percent were quality Type II and Type IV, respectively. Quality Type I and Type V combined contribute to the remaining 5 percent of vessels. In contrast, more quality Type IV (43\%) and Type V (22\%) vessels were found in caves from the Late Ming (LM) period. Quality Type III, the most common in the Middle Ming period, only contributed 17 percent of the total vessel quantities during the Late Ming period. The comparison reveals that the overall quality of blue-andwhite porcelain consumption for the communities using these cave sites declined after the Spanish colonization.

Table i. Summary of Quality Distribution for Blue-And-White Porcelain in All Cave Sites

\begin{tabular}{|l|c|c|c|c|c|c|}
\hline PERIOD & TYPE I & TYPE II & TYPE III & TYPE IV & TYPE V & TOTAL \\
\hline Mid Ming & $1(0.6 \%)$ & $32(20.5 \%)$ & $81(51.9 \%)$ & $34(21.8 \%)$ & $8(5.1 \%)$ & 156 \\
\hline Late Ming & $7(4.8 \%)$ & $19(12.9 \%)$ & $25(17.0 \%)$ & $63(42.9 \%)$ & $33(22.4 \%)$ & 147 \\
\hline
\end{tabular}


The total quantity of Ming blue-and-white porcelain specimens, which spread over many caves across the southern Philippines, appears roughly the same for the Middle Ming and Late Ming periods. Since these data from Guthe's expedition are not a random sample, sheer quantity cannot be taken as a sufficient indication of trade volume. A closer look helps to break the caves down into two groups: those that have blue-and-white porcelain from both periods and those that only have blue-and-white porcelain from one of the two periods concerned. Since caves in the former group may have been used as burial locations for the same social group, the figures from the two periods are related. A paired t-test was used to address the difference in these paired data.

Of fifteen caves that were used in both periods, the mean vessel quantity during the Middle Ming period is 10.0 with a standard deviation (SD) of 10.5; the mean during the Late Ming period is 5.1 with a SD of 4.5. A paired t-test revealed no significant differences between the average number of vessels for the two periods, $t(14)=1.75$, $p=0.101$. Without assuming normal distribution for the number of vessels, a Wilcoxon Signed Ranks test was conducted and the results confirmed that there was no significant difference between the two periods.

For the remaining fifteen caves that only had blue-and-white porcelain from one of the two periods concerned here, 3 were from the Middle Ming period (2 vessels per cave) and 12 were from the Late Ming period (an average 5.8 vessels per cave, S1:19.5). Caves from the Late Ming period were so different mainly because of two outliers (C64LM with 32 vessels, and C8OLM with 17 vessels). With such unbalanced data, there is no good statistical test for comparison.

The paired t-test for caves with porcelain from both periods was conducted with the assumption that the deposits formed over the same duration. Once the time dimension was factored in, the pattern favors a decrease of Chinese blue-and-white porcelain over time. The Middle Ming period (1465-1522) covered only 57 years while Late Ming (1522-1644) lasted 122 years. This suggests that in the average decade, each Middle Ming cave-using group deposited an average of about 1.8 vessels, while each Late Ming Group using the same cave only put in an average of about 0.4 vessels. Therefore, the Middle Ming cave-using groups included four times the imported Chinese blue-and-white porcelain in their cave burials as their Late Ming successors.

Although we cannot assume that the same social group was responsible for the remains in a single cave over the two periods, it is nevertheless plausible that groups using the same cave shared similar social, economic, and ecological circumstances. Analysis suggests a decline in both quality and quantity of porcelain consumed from the Middle Ming to Late Ming by cave-using social groups across the southern Philippines.

Caution has to be practiced in using the time dimension. First, the production and export of the blue-and-white porcelain did not take place at an even pace. Instead, there were peaks and valleys in the production of each period in response to market demands, production organizations, political dynamics, and the effectiveness of government restrictions on maritime trade. Second, Spanish galleon trade in New World silver flourished in the later part of the Late Ming, and through the Transitional Period. The duration of such global economic activities does not coincide nicely with the duration of "Late Ming" as a category for ceramic chronology. Third, the nature of the Guthe Collection can further complicate the picture. While some specimens were excavated and include many small fragments, others may have been purchased 
on the spot by his agents, and are thus more likely to be complete pieces. This unsystematic data collection may have introduced bias to the analysis. Therefore, these patterns should be taken as indications of a broad economic trend rather than as precise figures.

\section{Burial Sites}

Artifact numbers starting with the letter B in the Guthe field catalog generally refer to materials collected from cemetery sites in open spaces rather than cave sites. It is important to consider burials separately from caves because these burials were often more closely associated with settlements than caves were (indeed, some of these sites may be settlement sites) and these burials may represent a different funerary tradition from those burying their dead in caves. The quality of information on these burials, however, varies significantly from site to site.

The quality distribution of Middle and Late Ming (including the Transitional Period) blue-and-white porcelain from burial sites is summarized in Table 2. Numbers represent quantity of potsherds for each quality grade and percentage represents the proportion of a quality grade during each period. Detailed counts of potsherds in every quality grade by each burial site are presented in Appendix II.

A chi-square test reveals a significant association between time period and vessel qualities, $x^{2}=29.306, d f=4, p<0.001$. The Middle Ming pattern for burial sites is rather similar to the distribution in the cave sites, with Type III specimens representing the largest share (47\%) followed by Type IV and II. In contrast, the more frequent quality types observed for the Late Ming were Type I (9\%) and Type II (28\%). The Middle Ming period showed only approximately 1 percent and 13 percent for Type I and Type II, respectively. Although the percentages of quality Type IV and Type V remained approximately the same during the two periods, Type IV had the largest proportion in the Late Ming period (31\%). This figure seems to show a polarizing pattern for the quality of blue-and-white porcelain, with an increase at both ends of the quality spectrum at the expense of middle quality groups.

The data, however, are skewed by three major sites: B4 (57 potsherds), B15 (133 potsherds), and B96 (87 potsherds), which make up to 84 percent of the Late Ming blue-and-white porcelain from burial sites. Once these three outliers are removed, a new chi-square test on remaining burial data shows that there is a significant association between quality type and periods; $\mathrm{x}^{2}=19.811, \mathrm{df}=4, \mathrm{p}=0.001$ (Table 3). The quality distribution in these burial sites shows similar patterns as the caves, where Type IV (57\%) wares represent the largest share.

In examining quantity changes in burial data over time and to address the issue of data dependency, I again divided the data into two groups: those with material from

Table 2. Summary of Quality Distribution for Blue-And-White Porcelain in All Burial Sites.

\begin{tabular}{|l|c|c|c|c|c|c|}
\hline PERIOD & TYPE I & TYPE II & TYPE III & TYPE IV & TYPE V & TOTAL \\
\hline Mid Ming & $1(1.2 \%)$ & $11(12.8 \%)$ & $40(46.5 \%)$ & $25(29.1 \%)$ & $9(10.5 \%)$ & 86 \\
\hline Late Ming & $28(8.5 \%)$ & $91(27.5 \%)$ & $68(20.5 \%)$ & $104(31.5 \%)$ & $40(12.1 \%)$ & 331 \\
\hline
\end{tabular}


Table 3. Quality Distribution for Blue-and-White Porcelain in Burial Sites (ExCLUding B4, Bi5, AND B96).

\begin{tabular}{|l|c|c|c|c|c|c|}
\hline PERIOD & TYPE I & TYPE II & TYPE III & TYPE IV & TYPE V & TOTAL \\
\hline Mid Ming & $1(1.2 \%)$ & $11(12.8 \%)$ & $40(46.5 \%)$ & $25(29.1 \%)$ & $9(10.5 \%)$ & 86 \\
\hline Late Ming & $5(9.3 \%)$ & $3(5.6 \%)$ & $13(24.1 \%)$ & $31(57.4 \%)$ & $2(3.7 \%)$ & 54 \\
\hline
\end{tabular}

Table 4. Quality Distribution for Blue-And-White Porcelain in Burial Sites IN $\mathrm{B}_{4}$, B I5, AND B96.

\begin{tabular}{|c|c|c|c|c|c|c|}
\hline SITE & TYPE I & TYPE II & TYPE III & TYPE IV & TYPE V & TOTAL \\
\hline B4 & $1(2 \%)$ & $5(9 \%)$ & $8(14 \%)$ & $28(49 \%)$ & $15(26 \%)$ & 57 \\
\hline B15 & $17(13 \%)$ & $47(35 \%)$ & $21(16 \%)$ & $31(23 \%)$ & $17(13 \%)$ & 133 \\
\hline B96 & $5(6 \%)$ & $36(41 \%)$ & $26(30 \%)$ & $14(16 \%)$ & $6(7 \%)$ & 87 \\
\hline
\end{tabular}

both periods and those with material from only one period. The three outliers were removed from this analysis and examined separately.

Nine burial sites were used during both periods. The means and SDs of items are 2.9 and 3.1 for the Middle Ming group and 2.9 and 2.6 for the Late Ming group. A Wilcoxon Signed Ranks test (0.734) suggests that the difference between the two groups is not significant. Among the 36 burial sites used only during one period, 17 are from the Middle Ming group and 19 from the Late Ming group. On average, the Middle Ming group has 1.6 items per site and the Late Ming group has 1.9 items. An independent t-test shows that the two groups do not significantly differ in the mean numbers of items, $\mathrm{t}(36)=1.021, \mathrm{p}=0.314$. Using the logic adumbrated above for cave sites, the lack of significant difference in the quantity of items placed in burials between the two periods probably means a decrease in number, as the duration of the Late Ming period is much longer than the Middle Ming.

The quality distribution for blue-and-white porcelain from the three outliers is presented in Table 4. A comparison of Tables 4 and 3 shows that B4 shares a similar distribution pattern with the rest of the burial ground sites and the cave features, with more than half of the specimens in the low quality category (Type IV and V).

In contrast, nearly half of the specimens in the fine categories (Type I and II) show up in sites B15 and B96, which share a similar pattern. Such variation marks a departure from the Middle Ming pattern in caves and burials where the majority is in the middle quality range with few at the ends of spectrum. The evidence suggests that some sites display a concentration of fine porcelain wares in the Late Ming period, against the general decline in the quality of imported blue-and-white porcelain.

This contrast presents interesting questions for understanding early colonial dynamics in the Philippines. Guthe's field notes in the University of Michigan Museum of Anthropology archives suggest that both locales were associated with early Spanish colonization. Burial ground B96, was associated with an old grave on Sulu Island, "said to have been that of one of the first missionaries to this country." (Guthe 19221925 : n.p.). Burial ground B15 at Dapita, Mindanao was near fortifications built by a chief to protect his people against the invading Moros troops sent by the Sulu 
sultan. Later, this became the site of a Spanish garrison where Guthe claimed he found "curious relics of the first Christian converts among the early Moros" (Guthe 1922-1925 : n.p.). Pre-Hispanic and colonial occupation probably contributed to the rich porcelain potsherd scatter at the site, as Middle and Late Ming period blue-andwhite porcelain was found there in abundance.

Such accounts have to be taken with caution as Guthe did not write detailed records of all sites that he visited. It is not advisable to take the lack of such entries about other sites as evidence for absence of colonial involvement there. After all, it was not Guthe's mission to document archaeological evidence of Spanish colonization in the Philippines. Furthermore, Guthe's accounts do not confirm the Spanish provenience of these remains. Indeed, such confirmation was not the goal of my research on colonial dynamics as seen through material culture.

Whether or not these are the actual remains of a Spanish settlement, this evidence calls our attention to Philippine agency. Through providing military aid, conducting economic transactions, or intermarriage, the colonial encounter may have presented opportunities for some native social groups to access European resources. Philippine agency cannot be excluded from understanding indirect consequences of Spanish rule. The sheer presence of such variation in the Late Ming material is in itself a promising clue about broad political reconfigurations at the time. It can be further explored with information from other lines of evidence.

\section{Shifting Production Centers}

An examination of the locales where the blue-and-white porcelain vessels in the Guthe Collection were produced reveals a major shift over time. During the Middle Ming period, nearly all specimens analyzed in the burial sites and caves can be attributed to production in Jingdezhen and its hinterland. Of the Late Ming specimens analyzed, however, the majority (69\%) can be positively identified as Zhangzhou ware. The rest were made in Jingdezhen, its hinterland, and in other Fujian kilns contemporaneous with Zhangzhou production. Among the Late Ming specimens, the Jingdezhen wares are generally of fine quality, while the majority of the Zhangzhou vessels are substandard. Furthermore, the distribution of fine Jingdezhen porcelain is not random. They are concentrated in a few sites, particularly those associated with colonial contexts, such as B15 and B96. Since there is a significant association between production center and the general quality level of its products, this shift marks a general decline in native access to fine porcelains after the Spanish colonization. Such a dramatic shift cannot be explained away with the sole assertion that production was reorganized because Philippine consumers cared little about quality.

\section{DISCUSSION AND CONCLUSION}

Due to their religious and social significance, trade ceramics became an instrument of power in the political arena of the protohistoric Philippines (Junker 1999). If the Ming blue-and-white porcelain can be taken as a reliable indication of native involvement in the traditional Asiatic trade network, the pattern of distribution found in the Guthe Collection shows that after Spanish colonization, native power was probably reduced and reconfigured. Such reduction is manifested in the decline in both the quality of imported blue-and-white porcelain and in the quantity, which is seen in the majority of Late Ming period features. 
This likely resulted from a combination of factors, including: loss of control over major ports to the Spanish; interruption of native political relations by the imposition of a colonial administration; later reduction of cargo value due to Dutch piracy; and finally the redefinition of the Philippines in Asian and global trade structures due to its emergent role in the transshipment of New World silver. The last factor is particularly significant. By this time, Chinese junks returned from the Philippines to Fujian and Guangdong loaded with a single kind of merchandise: silver coins shipped to Manila from the New World on the Manila Galleon. The exchange rate for silver in China was so high that trade remained lucrative even if Chinese maritime enterprises sold only low-quality merchandise at very low prices. As competition for silver increased, the demand for native products diminished. In turn, fine porcelain that had been destined for port princes and native chiefs in the precolonial period now fetched better prices in silver from Europeans than from their traditional consumers. If control of trade had been, as has been argued, a key component of wealth and political power among Philippine elites, they now lost both their political base and source of income.

This complex reconfiguration of the Asiatic trade that connected the Philippines with the broader Asian and global contexts calls for a reconsideration of the concept of "homogenization" associated with the chiefly competition model (Nishimura 1992). In contrast to an apparent continuum in access to imported goods during the precolonial period, as one would expect from the lack of stratification in chiefdomlevel societies, the distribution pattern became more polarized. Some sites have a concentration of fine grade Jingdezhen ware, presumably obtained by those actively engaged in the colonial encounter, while other sites, probably settled by those displaced from the historic Asiatic trade network, show a general decline in quality and quantity. This contrast reveals that Zhangzhou production does not provide evidence for, nor was it a result of, "homogenization" despite the apparent monotony in the type and design repertoire of Zhangzhou products. Instead, the introduction of Zhangzhou ware in the Philippine market during the late sixteenth century took place at a time when significant variation in quality and quantity started to appear between sites. The production of Zhangzhou ware started in Fujian after the Spanish colonization of the Philippines, in response to the same globalizing forces that effectively put an end to the native social structure responsible for the "homogenization" process associated with chiefly competition.

The Philippine experience as seen from the perspective of the porcelain trade and consumption represents a different mode of colonization from that seen in the New World. Whereas native peoples were directly conquered and exploited in the New World, in the Philippines their involvement in the traditional Asiatic trade network was marginalized. This is similar to Portugal's impact on other parts of the Old World (Subrahmanyam 2001). The quality decline, design change, and reorganization of production for this market were among the many ways that the uneven processes of globalization manifested in different parts of the world.

What does the colonial experience in the Philippines, as seen through material culture, have to offer for understanding the broader theme of the advent of early modern society? This research presents an archaeological study of early modernity in an unlikely place: among chiefdom societies in the southern Philippines. The unique appeal of the Guthe blue-and-white porcelains lies in the potential for exploring an elaborate structure of interactions, where indigenous political development was juxtaposed with the global competition of empires and changing economic dynamics. As such, the presence of trade porcelain in the Philippines is not simply evidence of 
long-distance trade, it is also evidence for a transformation in social relations and the political apparatus associated with the movement of goods. Such a study allows us to consider how material culture articulates with the making of the modern world, the repercussions of which continue to be felt today.

Appendix I. Quality Distribution of Ming Blue-and-White Porcelain in Cave Sites Organized by Period

\begin{tabular}{|c|c|c|c|c|c|c|}
\hline & TYPE I & TYPE II & TYPE III & TYPE IV & TYPE V & TOTALS \\
\hline C16EM & 1 & & & & & \\
\hline C3MM & & 2 & & & & \\
\hline C5 MM & & 1 & & & & \\
\hline C7MM & & 2 & 2 & & & \\
\hline C9MM & & & 2 & & & \\
\hline C11MM & 1 & 4 & 18 & 8 & & \\
\hline C12MM & & & 2 & & & \\
\hline C16MM & & 1 & 7 & 3 & & \\
\hline C17MM & & 9 & 11 & 5 & 1 & \\
\hline C18MM & & & 4 & 2 & 2 & \\
\hline C19 MM & & & 5 & 5 & 1 & \\
\hline C22MM & & & 2 & & & \\
\hline C23MM & & 6 & 12 & 9 & 2 & \\
\hline C44MM & & 1 & & 1 & & \\
\hline C55 MM & & 4 & 7 & & 1 & \\
\hline C58 MM & & & 1 & & & \\
\hline C56 MM & & 1 & 7 & 1 & & \\
\hline C69 MM & & & 1 & & 1 & \\
\hline C84 MM & & 1 & & & & \\
\hline C14LM & & 2 & 2 & 1 & & \\
\hline C11LM & & & & 3 & 1 & \\
\hline C7 LM & & 1 & & & & \\
\hline C18 LM & & 1 & 3 & 5 & 1 & \\
\hline C16 LM & 1 & 6 & 5 & 2 & 1 & \\
\hline C17LM & & & & 1 & & \\
\hline C19 LM & 2 & 1 & & 2 & 1 & \\
\hline C22 LM & & 1 & 2 & 4 & 4 & \\
\hline C23LM & & & & 2 & 9 & \\
\hline C33LM & & & & 1 & & \\
\hline C41LM & & 1 & & & & \\
\hline C43LM & & & & 1 & & \\
\hline C45LM & 2 & & & & & \\
\hline C46LM & & & 1 & 2 & & \\
\hline C55LM & 1 & & & & & \\
\hline C56LM & & & & 3 & 1 & \\
\hline C58LM & & & & 1 & & \\
\hline C64LM & & & 4 & 20 & 8 & \\
\hline C69LM & & & & 2 & 2 & \\
\hline C70LM & & & 4 & 1 & 3 & \\
\hline C79LM & & & 1 & & & \\
\hline C81LM & & & & 1 & & \\
\hline C83LM & & 1 & & 1 & & \\
\hline C84LM & & & & 1 & & \\
\hline C9 $\mathrm{LM}+\mathrm{TR}$ & & & 2 & 1 & & \\
\hline C5 TR & 1 & 5 & 1 & 8 & 2 & \\
\hline
\end{tabular}

$\mathrm{EM}=$ Early Ming; $\mathrm{MM}=$ Mid Ming; $\mathrm{LM}=$ Late Ming; $\mathrm{TR}=$ Transitional Period.

Numbers represent quantity of potsherds in every quality grade in each site. 
Appendix II. Quality Distribution of Ming Blue-And-White Porcelain Potsherd Burial Sites

\begin{tabular}{|c|c|c|c|c|c|}
\hline & TYPE I & TYPE II & TYPE III & TYPE IV & TYPE V \\
\hline B3MM & & & 2 & 2 & 1 \\
\hline B4MM & & 2 & 10 & 7 & 4 \\
\hline B8MM & & 1 & & & \\
\hline B15MM & & 4 & 3 & 1 & \\
\hline B31MM & & 1 & & & \\
\hline B37MM & & & 2 & 1 & \\
\hline B46MM & & & 1 & 1 & \\
\hline B47MM & & & 1 & & \\
\hline B54MM & & & & 1 & \\
\hline B61MM & & & & 1 & 1 \\
\hline B62MM & & & 1 & & \\
\hline B69MM & & 1 & 1 & & \\
\hline B72MM & & & 1 & 1 & \\
\hline B77MM & & 1 & 6 & 3 & 1 \\
\hline B80MM & & & & 1 & \\
\hline B81MM & & 1 & & & \\
\hline B88MM & & & 1 & & \\
\hline B91MM & & & & 3 & \\
\hline В93MM & & & 1 & & \\
\hline B96MM & & & 3 & & \\
\hline B97MM & & & & 1 & \\
\hline B102MM & & & & 1 & \\
\hline B104MM & & & 1 & & \\
\hline B112MM & & & 1 & & \\
\hline B117MM & & & & & 1 \\
\hline B119MM & & & 2 & & \\
\hline B129MM & 1 & & 1 & & \\
\hline B132MM & & & 1 & & 1 \\
\hline B133MM & & & 1 & 1 & \\
\hline B4LM & 1 & 5 & 8 & 28 & 15 \\
\hline B10LM & 1 & & & 3 & \\
\hline B13LM & & 1 & & 2 & \\
\hline B14LM & & & 1 & & \\
\hline B15LM & 17 & 47 & 21 & 31 & 17 \\
\hline B20LM & & & 2 & & \\
\hline B21LM & & & & 1 & \\
\hline B43LM & & & & 1 & \\
\hline B44LM & & & & 1 & \\
\hline B46LM & & & & 1 & \\
\hline B49LM & & & & 1 & \\
\hline B60LM & & & 1 & & \\
\hline B69LM & & 1 & 1 & 4 & \\
\hline B71LM & & & & 1 & \\
\hline B73LM & & & 1 & & 1 \\
\hline B77LM & & & 1 & & \\
\hline B79LM & & & 3 & & \\
\hline B81LM & & & & 1 & \\
\hline B91LM & & & & 1 & \\
\hline B96LM & 5 & 36 & 26 & 14 & 6 \\
\hline B111LM & & & 1 & & \\
\hline B112LM & & & & 2 & \\
\hline
\end{tabular}

(Continued) 
ApPEndix II (Continued)

\begin{tabular}{|c|c|c|c|c|c|}
\hline & TYPE I & TYPE II & TYPE III & TYPE IV & TYPE V \\
\hline B113LM & & & & 1 & \\
\hline B114LM & & & & 1 & \\
\hline B115LM & & & & 1 & \\
\hline B116LM & & & 1 & & \\
\hline B126LM & & & & 1 & \\
\hline B128LM & & & & 1 & \\
\hline B129 LM & 4 & 1 & 1 & 2 & \\
\hline B132LM & & & & 2 & \\
\hline B133LM & & & & 3 & 1 \\
\hline
\end{tabular}

\section{REFERENCES CITED}

Abu-Lughod, Janet L.

1989 Before European Hegemony: The World System A.D. 1250-1350. New York: Oxford University Press.

ANDRADE, TONIO

2004 The Company's Chinese pirates: How the Dutch East India Company tried to lead a coalition of pirates to war against China, 1621-1662. Journal of World History 15(4) : 415-444.

Appadurai, Arjun, ED.

1986 The Social Life of Things: Commodities in Cultural Perspective. Cambridge: Cambridge University Press.

Bacus, Elisabeth A.

1995 Political Economy and Interaction: Late Prehistoric Polities in the Central Philippine Islands. Ph.D. diss. Department of Anthropology, University of Michigan, Ann Arbor.

1999 Prestige and potency: Political economies of protohistoric Visayan polities. In Complex Polities in the Ancient Tropical World. Archaeological Papers of the American Anthropological Association, No. 9:67-87, ed. Elisabeth Bacus and Lisa Lucero. Arlington, VA: American Anthropological Association.

Brown, RoxanNA

2004 The Ming Gap and Shipwreck Ceramics in Southeast Asia. Ph.D. diss. University of California, Los Angeles.

Carswell, John

1985 Blue-and-white in China, Asia, and the Islamic world. In Blue and White: Chinese Porcelain and Its Impact on the Western World: 27-35, ed. John Carswell, Edward A. Maser, and Jean McClure Mudge. Chicago: University of Chicago Press.

2000 Blue and White: Chinese Porcelain around the World. London: British Museum Press.

Chen, Jianzhong

1999 Dehua Minya Qinghua (Dehua folk blue-and-white wares). Beijing: Wenwu Press.

Cushner, Nicholas P.

1971 Spain in the Philippines: From Conquest to Revolution. Quezon City, Ateneo de Manila University; Rutland, VT: C. E. Tuttle Co.

FINLEY, ROBERT

1998 The pilgrim art: The culture of porcelain in world history. Journal of World History 9(2) : 141187.

Flynn, Dennis, ANd Arturo GirëLdez

2004 Path dependence, time lags and the birth of globalization: A critique of O'Rourke and Williamson. European Review of Economic History 8: 81-108.

FOX, ROBERT B.

1959 The Calatagan excavations. Philippine Studies 7:325-390.

1967 The archaeological record of Chinese influence in Philippines. Philippine Studies 15(1):41-62. 
Frank, ANDre Gunder

1998 ReOrient: Global Economy in the Asian Age. Berkeley: University of California Press.

Fujian Provincial Museum

1997 Zhangzhou Yao [The Zhangzhou kilns]. Fuzhou: Fujian People's Publishing Co.

Ge Zhejia (annotation)

1992 Piaohai lu [accounts of shipwreck and journey] by Cui Bo. Beijing: Sheke wenxian chubanshe.

GODDIO, FRANCK

1988 Discovery and Archaeological Excavation of a 16th Century Trading Vessel in the Philippines. Lausanne, Switzerland: World Wide First.

2002 Lost at Sea: The Strange Route of the Lena Shoal Junk. London: Periplus.

Guthe, Carl E.

1922- Unpublished field notes, University of Michigan Philippine Expedition: Asian Division,

1925 Museum of Anthropology, University of Michigan.

1929 Distribution of sites visited by University of Michigan's Philippines Expedition, 1922-1925. Papers of the Michigan Academy of Science, Arts, and Letters 10:79-89.

Harrison-Hall, Jessica

2001 Ming Ceramics in the British Museum. London: The British Museum.

HARrisson, Barbara

1979 Swatow. Leeuwarden: Gemeentelijk Museum Het Princessehof.

HE, LI

1996 Chinese Ceramics: A New Comprehensive Survey from the Asian Art Museum of San Francisco. New York: Rizzoli.

Higgins, Roland

1981 Piracy disturbances and coastal defense in the Ming period: Government response to coastal 1523-1549. Ph.D. diss. Department of History, University of Minnesota.

HirTh, F., AND W. ROCKHILL

1966 Chau Ju-Kua: His Work on the Chinese and Arab Trade in the Twelfth and Thirteenth Centuries, Entitled Chu-Fan-Chi. Amsterdam: Oriental Press.

Ho, Chuimei

1988 Minnan Blue-and-White Wares: An Archaeological Survey of Kiln Sites of the Sixteenth-Nineteenth Centuries in Southern Fujian, China. Oxford: BAR International Series 428.

Huang Wei and Huang Qinghua

2007 Guangdong Taishan Shangchuandao Huawanping yizhi chutu ciqi ji xiangguan wenti [Research on the ceramics discovered at the Huawanping site, Shangchuan Island in Taishan, Guangdong]. Wenwu $5: 78-88$.

JUNKER, LAURA

1990 Long-Distance Trade and the Development of Socio-Political Complexity in Philippine Chiefdoms of the First Millennium to Mid-second Millennium A.D. Ph.D. diss. Department of Anthropology, University of Michigan, Ann Arbor.

1998 Integrating history and archaeology in the study of contact period Philippine chiefdoms. International Journal of Historical Archaeology 2:291-320.

1999 Raiding, Trading, and Feasting: The Political Economy of Philippine Chiefdoms. Honolulu: University of Hawai'i Press.

Kilburn, Richard S.

1981 Transitional Wares and Their Forerunners. Hong Kong: The Oriental Society of Hong Kong.

Kuwayama, George

1992 Chinese Ceramics in Colonial Latin America. Ph.D. diss. University of Michigan.

LI JIAN“AN

2005 Research on Zhangzhou Kiln. Report for the Tenth Five-year Plan Sponsored Project of Social Science in Fujian.

LI JINMING

2001 Zhangzhou Gang [The port of Zhangzhou]. Fuzhou: Fujian People’s Press.

Li Min AND Rachel Ji LeE

2007 Return to the celadon cave: Distribution of Chinese celadon in the Guthe Collection. Paper presented at the International Conference of Chinese Trade Ceramics, the National University of Singapore and the Singapore National Library. 
LitTLe, STEPHeN

1983 Chinese Ceramics of the Transitional Period: 1620-1683. New York: China House Gallery, China Institute in America.

Majul, Cesar Adib

1973 Muslums in the Philippines. Quezon City: University of the Philippines Press.

Medley, Margaret

1993 Organization and production at Jingdezhen in the sixteenth century. In The Porcelains of Jingdezhen: 69-82, ed. Rosemary Scott. Colloquies on Art and Archaeology in Asia, no. 16. London: Percival David Foundation of Chinese Art.

MiksIC, JoHN

2006 Chinese ceramics and the economics of early Southeast Asian urbanization, 14th to 16th centuries. Bulletin of the Indo-Pacific Prehistory Association 26:147-153.

Nishimura, Masao

1992 Long Distance Trade and the Development of Complex Societies in the Prehistory of the Central Philippines: The Cebu Central Settlement Case. Ph.D. diss. Department of Anthropology, University of Michigan, Ann Arbor.

Rinaldi, MaUra

1989 Kraak Porcelain: A Moment in the History of Trade. London: Bamboo Publisher.

Scott, Rosemary, And Rose Kerr

1994 Ceramic Evolution in the Middle Ming Period: Hongzhi to Wanli (1488-1620). London: Victoria and Albert Museum and Percival David Foundation of Chinese Art.

SCHURZ, William LytLe

1985 The Manila Galleon. New York: E. P. Dutton.

Solheim, W. G.

1964 The Archaeology of Central Philippines. Manila: National Science Development Board, National Institute of Science and Technology.

SU JIQING

1981 Daoyi zhilue jiaoshi [annotation of Wang Dayuan's Daoyi zhilue]. Beijing: Zhonghua shuju.

Subrahmanyam, SANJAY

2001 Written on water: Designs and dynamics in the Portuguese Estado da India. In Empires: 42-69, ed. Susan E. Alcock et al. Cambridge: Cambridge University Press.

TAN, Rita C.

1997 Development of Ming Minyao blue-and-white ware with reference to Philippines finds. In Chinese and Vietnamese Blue-and-white Wares Found in the Philippines: 79-108, ed. Larry Gotuaco, Rita C. Tan, and Allison I. Diem. Makati City: Bookmark Inc.

VOLKER, T.

1954 Porcelain and the Dutch East India Company. Leiden: Brill.

VON GLAHN, RichaRd

1996 Fountain of Fortune: Money and Monetary Policy in China, 1000-1700. Los Angeles: University of California Press.

WiLls, John E. JR.

1979 Maritime China from Wang Chih to Shih Lang: Themes in peripheral history. In From Ming to Ch'ing: Conquest, Region, and Continuity in Seventeenth-Century China: 202-238, ed. Jonathan D. Spence and John E. Wills Jr. New Haven: Yale University Press.

1998 Relations with maritime Europeans, 1514-1662. In The Cambridge History of China, vol. 8: The Ming Dynasty, 1368-1644, part 2, ed. Denis Twitchett and Frederick W. Mote. Cambridge: Cambridge University Press.

Wolf, Eric R.

1982 Europe and the People Without History. Berkeley: University of California Press.

WONG, Grace

1978 Chinese blue-and-white porcelain and its place in the maritime trade of China. In Chinese Blue and White Ceramics, ed. S. T. Yeo and Jean Martin. Singapore: Arts Orientalis.

ZeNG FAN

2001 Fujian Taoci Kaogu Gailun [Survey of ceramic archaeology in Fujian]. Fuzhou: Fujian Provincial Atlas Press. 
ZhANG Zhongshun

1989 Ming Qing shiqi de Fujian Anxi qinghua ciqi [Blue-and-white porcelain of the Ming and Qing periods from Anxi, Fujian]. Kaogu 7:617-623.

Zheng GuANGNAN

1998 Zhongguo Hai Dao Shi [History of piracy in China]. Shanghai: Eastern China Polytech University Press.

\begin{abstract}
Archaeology provides a powerful lens for revealing the complex social processes and profound consequences of global encounters. This study of archaeological ceramics from the southern Philippines investigates patterns of quality, source variation, and spatial distribution for Chinese trade porcelain dating before and after Spanish colonization. It aims at placing archaeological research on ceramics trade into the broader context of trans-Pacific trade between East Asia and Spanish America, as well as the historical circumstances for the production, distribution, and consumption of commodities involved in the global exchange. The patterns documented reveal continuity and transformation of the Asiatic trade network and the diverse responses to the colonial condition by native communities. The ceramic trade and indigenous political development were juxtaposed with the global competition of empires and changing economic dynamics. KeYwOrDs: early modern trade, porcelain, chiefly society, Philippines, Manila Galleon, Zhangzhou ceramics.
\end{abstract}

